\title{
Dynamic and Thermodynamic Modulators of European Atmospheric Rivers
}

\author{
BREANNA L. ZAVADOFF AND BEN P. KIRTMAN \\ Rosenstiel School of Marine and Atmospheric Science, University of Miami, Miami, Florida
}

(Manuscript received 8 August 2019, in final form 13 February 2020)

\begin{abstract}
Large-scale analysis of the dynamic and thermodynamic properties of landfalling atmospheric rivers (ARs) over western Europe is performed utilizing 38 years of the Modern-Era Retrospective Analysis for Research and Applications, version 2 (MERRA-2), reanalysis dataset. A climatology of landfalling ARs from 1980 to 2017 is developed using a combination of integrated water vapor transport (IVT) calculations and a detection algorithm, which identified 578 ARs over the study period. Examination of the upper-level potential vorticity (PV) fields shows that $73 \%$ of these AR events are related to anticyclonic Rossby wave breaking (RWB), a dynamic feature which has been shown to play a role in AR strength and structure. Atmospheric river variability is also found to be closely tied to jet-stream latitude modulation by the North Atlantic Oscillation (NAO), such that during a positive NAO the North Atlantic jet is shifted north, creating an environment that is more favorable for anticyclonic RWB and AR landfalls over northern Europe, and during a negative NAO it is shifted south, creating such an environment over southern Europe. Through the use of linear regression analysis, AR strength is shown to be dependent on atmospheric moisture availability, which is found to increase as sea surface temperatures (SSTs) increase. Therefore, in a warming climate warmer SSTs leading to higher atmospheric moisture availability will result in an increase in the average strength and intensity of ARs over western Europe-a trend that has already been observed.
\end{abstract}

\section{Introduction}

Atmospheric rivers (ARs), first identified by Newell et al. (1992), are narrow filaments of high water vapor content that extend thousands of kilometers (Zhu and Newell 1998), carry more water than 27 Mississippi Rivers combined on average (Ralph et al. 2017), and play integral roles in the global water cycle. Zhu and Newell (1998) estimated that four-five ARs are present in the atmosphere at any given time, accounting for greater than $90 \%$ of poleward water vapor transport to the midlatitudes despite covering a combined area of less than $10 \%$ of the circumference of Earth at those latitudes. Climatological studies have shown that ARs are most frequently found over midlatitude ocean basins (Knippertz and Wernli 2010; Knippertz et al. 2013; Guan and Waliser 2015) and most commonly develop during the winter because of their association with extratropical cyclones, which have a greater prevalence during the cold season because of a more active storm track (Lavers and Villarini 2015; Debbage et al. 2017). In the

Corresponding author: Breanna L. Zavadoff, bzavadoff@rsmas. miami.edu
Northern Hemisphere ARs primarily make landfall over the U.S. West Coast and western Europe (Guan and Waliser 2015), making both regions active areas for AR research.

For both the western United States and western Europe ARs have been established as crucial components of the hydrological cycle, because they provide each region with $20 \%-30 \%$ of their annual precipitation (Neiman et al. 2008; Lavers and Villarini 2015). In addition, over the western United States, ARs have been found to be responsible for breaking $60 \%-74 \%$ and $33 \%-40 \%$ of persistent droughts in the Pacific Northwest and California, respectively (Dettinger 2013). Despite these benefits, ARs have also been responsible for the development of extreme, long-lasting precipitation events that can lead to devastating local flooding over the western United States (Higgins et al. 2000; Ralph et al. 2006; Neiman et al. 2008; Ralph and Dettinger 2011, 2012; Neiman et al. 2011; Warner et al. 2012), the United Kingdom (Lavers et al. 2011, 2012), the Iberian Peninsula (Fragoso et al. 2010; Liberato et al. 2012; Trigo et al. 2014; Ramos et al. 2015), and Europe as a whole (Lavers and Villarini 2013). Because of both their enormous benefits and threats to human life and infrastructure, over the past two decades 
many studies have been performed to characterize landfalling ARs in terms of their surrounding synoptic-scale environment and dynamics.

A multitude of studies focused on describing the anomalous large-scale flow patterns associated with ARs over both the U.S. West Coast and western Europe have demonstrated that the synoptic environment leading up to landfalling ARs in each region are almost identical. For instance, both U.S. West Coast and western European landfalling AR events are characterized by the emergence of positive geopotential height and sea level pressure anomalies to the southeast and negative geopotential height and sea level pressure anomalies to the northwest of the region where the AR makes landfall (Lackmann and Gyakum 1999; Higgins et al. 2000; Neiman et al. 2008; Lavers et al. 2011; Lavers and Villarini 2013; Payne and Magnusdottir 2014; Mundhenk et al. 2016b). Consequently, the anomaly dipole produces anomalously strong upper- and lower-level southwesterly winds that blow toward the coast. This finding suggests that the anomaly patterns modulate where the southwesterly wind anomalies develop, controlling where ARs will form and thus make landfall. In addition, in both regions the anomalous southwesterly flow was found to be collocated with positive moisture anomalies oriented southwest to northeast that extend back into the (sub)tropical North Pacific Ocean, reinforcing the assertion of previous studies that ARs are fueled by moisture transported from the (sub)tropics to the extratropics (Neiman et al. 2008; Lavers et al. 2011).

In addition to characterizing large-scale flow patterns surrounding ARs, a number of studies have also focused on the role climate modes play in modulating the frequency and location of ARs in hopes of increasing their predictability. Studies by Ryoo et al. (2013) and Payne and Magnusdottir (2014) have demonstrated that during an El Niño ARs are more likely to make landfall at lower latitudes along the U.S. West Coast as a result of a southerly shift in the North Pacific jet and conversely that during a La Niña ARs are more likely to make landfall at higher latitudes along the coast because of a northerly shift in the North Pacific jet. Furthermore, while Payne and Magnusdottir (2014) showed that the number of wintertime U.S. West Coast ARs landfalls are more or less frequent during El Niños or La Niñas, respectively, Mundhenk et al. (2016a) found the opposite trend when all months are taken into account. In addition, results from both Payne and Magnusdottir (2014) and Mundhenk et al. (2016a) indicate that AR activity along the U.S. West Coast generally increases during phases 7-8 and decreases during phases 2-5 of the Madden-Julian oscillation. Over western Europe, Lavers and Villarini (2013) and Brands et al. (2017) both observed that northerly displacement of the jet stream associated with a positive North Atlantic Oscillation (NAO) and southerly displacement associated with a negative NAO, along with the subsequent sea level pressure (SLP) anomalies that arise, translates to northern Europe experiencing a higher frequency of landfalling ARs when the NAO is in its positive phase and vice versa. It has also been noted by Lavers et al. (2012), Ramos et al. (2015), and Brands et al. (2017) that other climate indices such as the east Atlantic (EA) and Scandinavian (SCAND) patterns can significantly contribute to the variability of western European landfalling ARs in specific regions. Using a Poisson regression model, Lavers et al. (2012) showed that there was a negative correlation between the SCAND index and AR frequency over Great Britain. Ramos et al. (2015) demonstrated that, while a significantly strong positive correlation in AR variability over the Iberian Peninsula was found with the EA pattern, correlation with the NAO was low and insignificant. Both of these findings were supported by Brands et al. (2017); however, it was noted that when considering the region as a whole the influence of the NAO on AR frequency modulation was most significant. Only when focusing on specific regions during the October-December season did the two other indices exhibit a stronger influence.

In recent years a dynamical link between Rossby wave breaking (RWB), the rapid and irreversible deformation of potential vorticity (PV) contours on isentropic surfaces (McIntyre and Palmer 1983, 1984), and U.S. West Coast ARs has been uncovered that suggests RWB plays a role in modulating the development and trajectories of ARs (Sodemann and Stohl 2013; Ryoo et al. 2013; Payne and Magnusdottir 2014; Liu and Barnes 2015; Ryoo et al. 2015; Mundhenk et al. 2016b; Hu et al. 2017). Independent studies by Ryoo et al. (2013) and Sodemann and Stohl (2013) showed that AR trajectory pathways and the resulting locations of precipitation are related to the type of RWB occurring, such that ARs associated with anticyclonic RWB follow a northeastward trajectory, causing AR events and heavy precipitation to occur at higher latitudes, and ARs associated with cyclonic RWB follow an eastward trajectory, causing AR events and heavy precipitation to occur at lower latitudes. Further investigation into AR dynamics has shown that a majority of U.S. West Coast landfalling ARs are found to be located ahead of a region of high upper-level PV on the northwestward flanks of eastern Pacific anticyclonic RWB events (Payne and Magnusdottir 2014; Ryoo et al. 2015; Mundhenk et al. 2016b). This region proves to be favorable for AR development because it typically contains a low pressure center positioned to the northwest of a high pressure center, which produces a southwesterly flow that transports moisture from the 
tropics to the coast. The connection between U.S. West Coast landfalling ARs and anticyclonic RWB is further explained by the fact that both occur primarily on the equatorward side of the subtropical jet, whereas cyclonic RWB is more prevalent on the poleward side of the subtropical jet and thus interacts less with landfalling ARs in the region (Payne and Magnusdottir 2014; Mundhenk et al. 2016b).

While the state of the large-scale environment preceding landfalling ARs and their modulation by high- and lowfrequency climate modes have been well documented for both regions, large-scale extratropical processes such as RWB and their association with AR modulation and development has only been studied for U.S. West Coast ARs. Investigation into this RWB-AR connection has yet to be expanded to other parts of the globe where landfalling ARs are known to occur, despite proving to be a significant feature of ARs impacting the U.S. West Coast. Given the strikingly similar characteristics of the large-scale environment among U.S. West Coast and western European ARs as well as results from case studies by Knippertz et al. (2013) and Sodemann and Stohl (2013) that suggest extratropical PV patterns reminiscent of RWB can help drive AR-like moisture transport to western Europe, it is reasonable to hypothesize that RWB also plays a role in the modulation and development of European landfalling ARs. Therefore, the first objective of this paper is to build an all season climatology of ARs that make landfall over western Europe and analyze the environments surrounding these events to ascertain whether or not there is a relationship between ARs that develop in this region and RWB.

In addition to studying the environmental features and dynamics surrounding ARs, many studies have also concentrated on determining where the moisture fueling ARs originate and how changes in these moisture sources via global climate change may impact future AR intensities. Early studies into ARs, which focused primarily on the U.S. West Coast, noted that they are typically found ahead of cold fronts in the warm conveyor belts of extratropical cyclones (Ralph et al. 2004), develop through low-level moisture convergence, and get their moisture directly from the tropics, and the moisture is then transported to the extratropics (Bao et al. 2006; Knippertz and Wernli 2010). More recent back trajectory studies by Ryoo et al. (2015) and EirasBarca et al. (2017) support the hypothesis that moisture for U.S. West Coast ARs originate primarily in the tropics, however, a majority of the time air particle trajectories of subtropical and extratropical origin were also found mixing in with those from the tropics to make up the total moisture content. In slight contrast to their U.S. West Coast counterparts, Lavers et al. (2011),
Liberato et al. (2012), and Ramos et al. (2016) noted that European ARs acquire their moisture predominantly from the (sub)tropical North Atlantic Ocean between $20^{\circ}$ and $40^{\circ} \mathrm{N}$ and are supplemented by extratropical moisture sources near the AR landfalling location. This discrepancy could be explained by the fact that ARs over western Europe make landfall at much higher latitudes than those over the U.S. West Coast and, as pointed out by Ramos et al. (2016), an increase in AR latitude coincides with an increase in moisture source latitude.

Within the last decade the interest in how extreme weather events will be impacted by global climate change has skyrocketed, ARs being no exception. Using output from state of the art climate models, Dettinger (2011), Lavers et al. (2013), and Warner et al. (2015) each analyzed multiple simulations run with different emissions scenarios that ran through the end of the twenty-first century and all pointed to the same conclusion: in a warming world, AR intensities, regardless of region, will increase on average as a result of an overall increase in atmospheric moisture availability. This is due to a cascading effect rooted in the ClausiusClapeyron relationship, which states that as air temperatures increase saturation vapor pressure and the amount of atmospheric moisture increases (Lavers et al. 2013). Therefore, as a result of global climate change, ARs will have access to more moisture, allowing them to become stronger in the future. Given this projected change in AR intensities and the implication this has for the safety and well being of those in regions most commonly their devastating impacts, the second objective of this paper is to determine if these predicted changes in AR intensities can already be observed and, if so, the severity and drivers of these changes.

The remainder of this paper is organized as follows. Section 2 outlines the dataset and methods utilized to detect AR and RWB events, while section 3 discusses the climatology, synoptic and dynamic features, and variability of western European landfalling ARs. Section 4 discusses the results of linear regression analyses on thermodynamic features of ARs, and section 5 presents the summary discussion and conclusions of this study.

\section{Data and methods}

\section{a. Atmospheric river detection}

For this study, 38 years (1980-2017) of the National Aeronautics and Space Administration's Modern-Era Retrospective Analysis for Research and Applications, version 2 (MERRA-2), reanalysis dataset (Gelaro et al. 2017) will be used as a source for all atmospheric 
variables used in the analysis phase including specific humidity, horizontal winds, and PV. MERRA-2 was chosen over other reanalysis datasets due to its high spatial and temporal resolution as well the fact it and its predecessor were developed specifically for hydrological cycle applications (Rienecker et al. 2011). In this study, data will be retrieved at a 6 -hourly temporal resolution on a $1 / 2^{\circ} \times 5 / 8^{\circ}$ latitude-longitude grid.

Over the years, AR visualization has been primarily facilitated through either the integrated water vapor (IWV) or integrated vapor transport (IVT) spatial fields. First used by Ralph et al. (2004), satellite-derived IWV served as a proxy for AR moisture transport in lieu of IVT due to wind data aloft and wind direction information at the ocean surface not being readily available in satellite observations. However, IVT has proven to be a better for variable for AR visualization due to its usefulness in both understanding how ARs impact the global water cycle (Zhu and Newell 1998; Guan and Waliser 2015) and evaluating AR strength because it combines both wind and moisture data into a single quantity (Shields et al. 2018). As such, IVT will be utilized for AR visualization following the formula used in Lavers et al. (2012), Payne and Magnusdottir (2014), and multiple other studies to calculate the magnitude of IVT from 1000 to $300 \mathrm{hPa}$ as

$$
\mathrm{IVT}=\left[\left(\frac{1}{g} \int_{1000}^{300} q u d p\right)^{2}+\left(\frac{1}{g} \int_{1000}^{300} q v d p\right)^{2}\right]^{1 / 2},
$$

where $g$ is the acceleration due to gravity $\left(\mathrm{m} \mathrm{s}^{-2}\right), q$ is the specific humidity $\left(\mathrm{kg} \mathrm{kg}^{-1}\right), u$ is the zonal wind $\left(\mathrm{m} \mathrm{s}^{-1}\right)$, $v$ is the meridional wind $\left(\mathrm{m} \mathrm{s}^{-1}\right)$, and $d p$ is the pressure difference between adjacent pressure levels.

The first step in AR detection involves setting an IVT threshold to separate AR signatures from the background. To eliminate the effects of the seasonal cycle on atmospheric moisture concentration, IVT threshold values are calculated separately for each month. Using the method outlined in Lavers and Villarini (2013), thresholds are determined by finding the maximum IVT at 1200 UTC on each day from 1980 to 2017, binning the values into separate months, and then calculating the 85th percentile of the IVT for each month. The 85th percentile is chosen as the threshold value because it corresponds to the IVT of the most intense ARs (Lavers et al. 2012). Because the European coastline is northsouth-oriented and covers a large latitude range, latitudedependent IVT thresholds are calculated for $5^{\circ}$ latitude bins spanning from $35^{\circ}$ to $70^{\circ} \mathrm{N}$ along the $10^{\circ} \mathrm{W}$ meridian, which is chosen to ensure that all European landfalling ARs are detected.
Once the IVT thresholds for each region have been established, individual ARs are detected at each 6-hourly time step over the domain following the algorithm described in Lavers and Villarini (2013). IVT is calculated at all grid points between $35^{\circ}$ and $70^{\circ} \mathrm{N}$ along the $10^{\circ} \mathrm{W}$ meridian. The maximum IVT value is recorded and, if the 85th-percentile threshold for the corresponding $5^{\circ}$ latitude bin is exceeded, each meridian from $30^{\circ} \mathrm{W}$ to $25^{\circ} \mathrm{E}$ between $35^{\circ}$ and $70^{\circ} \mathrm{N}$ is scanned for its maximum IVT value, which is also recorded if it exceeds the original threshold. If 36 continuous longitude points are recorded (roughly equal to an average of $1500 \mathrm{~km}$ across the domain) the detected structure meets the minimum AR length requirement and the time step is recorded as containing an AR. If the identified AR persists for at least $18 \mathrm{~h}$ and shifts no more than $4.5^{\circ}$ latitude to the north or south of the initial IVT maximum throughout its lifetime it is recorded as an event; otherwise the data are discarded. Last, for events to be considered independent of one another they must be separated by at least more than 1 day (Lavers and Villarini 2013).

Since ARs are persistent features that can shift meridionally throughout their lifetime, it is possible for the detection algorithm used in this study to flag the same AR for two different $5^{\circ}$ latitude bins. To ensure these particular ARs are not accidentally double counted in the climatology, all detected ARs undergo a manual inspection to make sure they are recorded only once. This is done by reviewing the latitudes at which the maximum IVT values on the $10^{\circ} \mathrm{W}$ meridian exceeded the 85th percentile threshold throughout the AR's lifetime. If all the latitudes fall within the same $5^{\circ}$ latitude bin, the data are ignored as that particular AR is only recorded once. However, if the latitudes are spread between two different $5^{\circ}$ latitude bins, the AR is marked as being located in the $5^{\circ}$ latitude bin in which it was first detected and the duplicate data are discarded.

\section{b. Rossby wave breaking detection}

To determine whether or not European ARs are dynamically linked to RWB, the PV fields surrounding each AR are scanned for the presence of an RWB event. Following a similar method to that described in Zavadoff and Kirtman (2019) and Payne and Magnusdottir (2014), RWB detection will be performed utilizing 200-hPa $\mathrm{PV}$ because of its close proximity to the $350-\mathrm{K}$ isentrope, which is commonly used for RWB detection in the upper troposphere/lower stratosphere (McIntyre and Palmer 1983, 1984; Postel and Hitchman 1999). While both studies' detection algorithms focus on anticyclonic RWB, here they will be expanded to also account for cyclonic RWB. The two types of RWB will be distinguished by the 
TABLE 1. Values of the IVT thresholds $\left(\mathrm{kg} \mathrm{m}^{-1} \mathrm{~s}^{-1}\right)$ used to identify western European ARs at $10^{\circ} \mathrm{W}$ for each of the $5^{\circ}$ latitude bins. Thresholds are presented for each individual month as well as a yearly average. The last column contains the number of ARs detected over the course of the 38-yr climatology.

\begin{tabular}{|c|c|c|c|c|c|c|c|c|c|c|c|c|c|c|}
\hline Lat & Jan & Feb & Mar & Apr & May & Jun & Jul & Aug & Sep & Oct & Nov & Dec & Avg & No. ARs \\
\hline${ }^{\circ}-40^{\circ} \mathrm{N}$ & 555.2 & 524.2 & 541.5 & 454.3 & 467.3 & 507.9 & 492.6 & 517.4 & 694.4 & 688.0 & 668.9 & 663.9 & 564.6 & 34 \\
\hline $40^{\circ}-45^{\circ} \mathrm{N}$ & 720.5 & 654.9 & 587.5 & 500.4 & 5 & 577.7 & 642.3 & 6 & 703.2 & 784.3 & 763.6 & 6 & .7 & 84 \\
\hline $45^{\circ}-50^{\circ} \mathrm{N}$ & 742.0 & 666.0 & 645.2 & 582.0 & 573.8 & 618.9 & 685.9 & 692.4 & 730.2 & 865.0 & 803.8 & 802.1 & 700.6 & 135 \\
\hline $50^{\circ}-55^{\circ} \mathrm{N}$ & 785.1 & 638.1 & 637.8 & 491.0 & 559.8 & 667.3 & 629.9 & 746.7 & 778.6 & 774.3 & 748.3 & 727.4 & 682.0 & 138 \\
\hline $55^{\circ}-60^{\circ} \mathrm{N}$ & 674.6 & 634.7 & 585.7 & 539.0 & 512.4 & 567.8 & 659.1 & 728.9 & 848.6 & 775.5 & 678.0 & 787.0 & 665.9 & 98 \\
\hline $60^{\circ}-65^{\circ} \mathrm{N}$ & 596.3 & 531.7 & 536.7 & 481.2 & 507.6 & 568.3 & 626.8 & 630.3 & 739.5 & 684.3 & 609.2 & 626.6 & 594.9 & 60 \\
\hline $65^{\circ}-70^{\circ} \mathrm{N}$ & 519.6 & 543.7 & 468.0 & 396.9 & 451.0 & 470.5 & 507.3 & 534.0 & 599.8 & 573.5 & 510.5 & 529.0 & 508.7 & 29 \\
\hline
\end{tabular}

orientation of the overturning PV contours, such that a southwest-northeast orientation is indicative of anticyclonic RWB and a northwest-southeast orientation is indicative of cyclonic RWB. Cyclonic RWB events must also exhibit a negative longitudinal PV gradient about the break, while anticyclonic RWB events must exhibit a positive longitudinal PV gradient about the break. For this study, the latitudinal PV gradient reversal criteria will be relaxed slightly, such that any PV tongue $\geq 2.5$ PVU (1 PVU $=10^{-6} \mathrm{~K} \mathrm{~kg}^{-1} \mathrm{~m}^{2} \mathrm{~s}^{-1}$ ) located equatorward of a region of low $\mathrm{PV}$ and spanning a minimum longitudinal extent of $10^{\circ}$ will be considered to be an RWB event. If none of the above criteria are satisfied and the PV field does not fit into either the cyclonic or anticyclonic categories, it is given the label of "other."

Once the RWB detection is completed, the IVT and PV fields, serving as proxies for the associated AR and RWB events, respectively, are analyzed from $T-1$ to $T+1$ day relative to the AR event at 6-hourly time steps to ascertain if European ARs have some connection to RWB. More specifically, if an anticyclonic RWB event is present and a connection exists, the IVT signature is expected to be embedded on the northwestward flank of the overturning PV contours, behind the high-PV tongue. In the case of a cyclonic RWB event being present, the IVT signature is expected to be embedded on the eastern flank of the overturning PV contours, ahead of the high-PV tongue, as demonstrated in Liu and Barnes (2015).

\section{Climatological analysis}

The 85th-percentile IVT thresholds, broken down by month and averaged over the entire year, and the number of ARs detected for each $5^{\circ}$ latitude bin are summarized in Table 1. Over the course of the 38-yr climatology a total of 578 landfalling ARs, averaging to approximately 15 events per year, were detected over western Europe. While Lavers and Villarini (2013) had only detected 432 ARs over a 33-yr period, thus averaging 13 events per year, the two sets of results are generally consistent with one another. This is because this study's IVT thresholds are broken down by month, allowing for ARs below the average threshold for the entire climatology, and thus a greater number of ARs overall and per year, to be identified by the detection algorithm. Additionally, in agreement with both Lavers and Villarini (2013) and Ramos et al. (2016), the highest IVT values are found from $45^{\circ}$ to $55^{\circ} \mathrm{N}$, which is collocated with the region where the greatest number of AR events are detected throughout the climatology (Fig. 1).

Following AR detection, the 200-hPa PV fields surrounding each $\mathrm{AR}$ were examined to ascertain whether these events have a connection to RWB. The results of this analysis, presented in Fig. 2, show that of the 578 landfalling ARs detected, 423, or approximately $73 \%$, were found to be collocated with anticyclonic RWB, a similar percentage to U.S. West Coast ARs (Ryoo et al. 2015; Mundhenk et al. 2016b). Of the remaining 155 ARs detected, only 21 were related to cyclonic RWB-a proportion that is considerably lower than those found

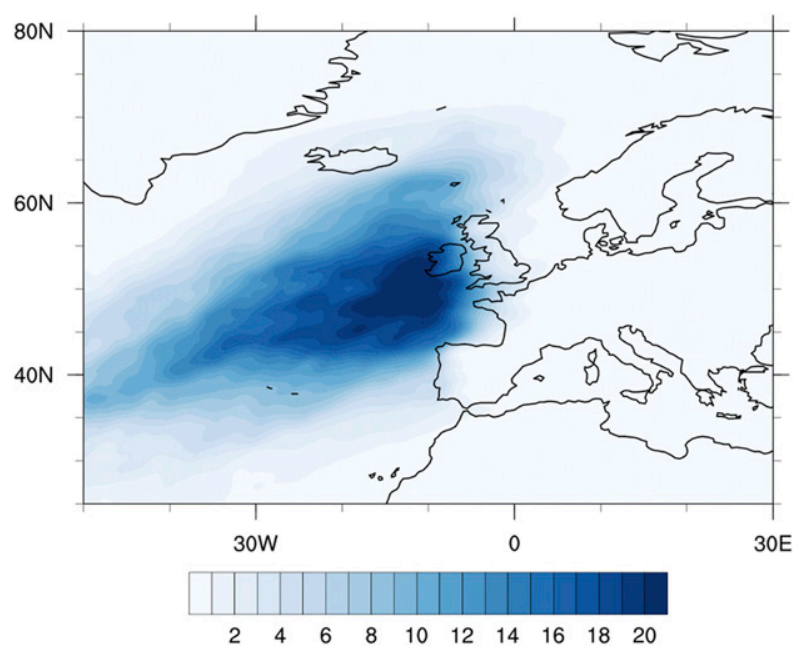

FIG. 1. Frequency distribution (shaded according to the color bar; \%) of the 578 AR events detected over western Europe throughout the climatology. 


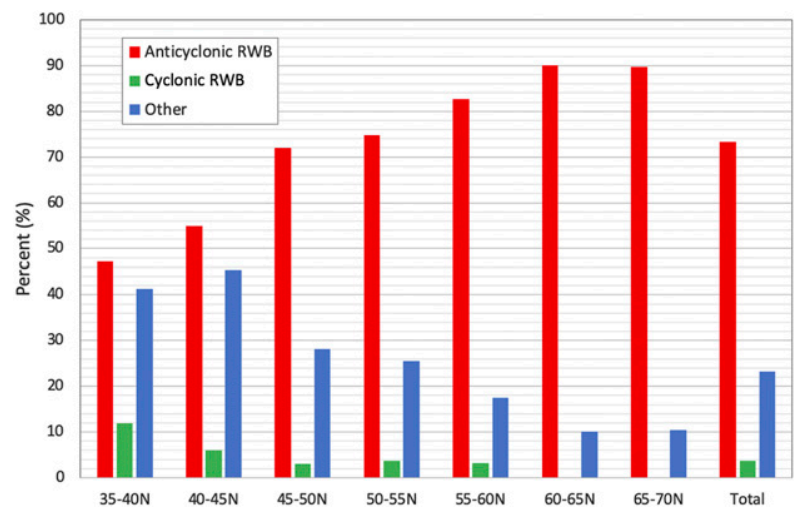

FIG. 2. Histogram of the percentages of RWB associated with each $A R$ event separated by $5^{\circ}$ latitude bin and, in the last grouping, over the course of the climatology. The three categories are: anticyclonic RWB (red), cyclonic RWB (green), and other (blue). Percentages are relative to the total number of ARs in each latitude bin.

in related studies over the U.S. West Coast, while the rest had PV patterns that did not fit into the anticyclonic or cyclonic RWB categories and were categorized as other. A quick analysis of the frequency of anticyclonic RWB over western Europe reveals that, on average, 43 anticyclonic RWB events occur in the region per year. This result, combined with the fact that approximately 11 ARs per year are collocated with anticyclonic RWB, indicates that this AR-RWB connection is very significant, as approximately one-quarter of all anticyclonic RWB events over western Europe are collocated with an AR. Additionally, in good agreement with studies by Payne and Magnusdottir (2014) and $\mathrm{Hu}$ et al. (2017) that focus on ARs impacting the U.S. West Coast, European ARs collocated with anticyclonic RWB are shown to be located behind the overturning high-PV tongue on northwestward flank of the RWB event (Fig. 3) and are carried to the north and east by the associated anomalous anticyclonic circulation.

\section{a. Synoptic and dynamic features}

To gain a better understanding of the environment around each group of ARs and to see how those that are and are not collocated with anticyclonic RWB compare to one another, Figs. 4 and 5 show composites of IVT, SLP, and 200-hPa PV for all ARs (Figs. 4a-d and 5a-c), ARs collocated with anticyclonic RWB (Figs. 4e-h and 5d-f), and ARs without anticyclonic RWB (Figs. 4i-1 and $5 \mathrm{~g}-\mathrm{i})$ separated by $5^{\circ}$ latitude bin. Focusing on the PV contours in the full composites (Figs. $4 a-d$ and $5 \mathrm{a}-\mathrm{c}$ ), each depicts a PV field that is deformed in an overturning pattern that gets clearer and stronger with latitude, indicative of the prevalence of anticyclonic RWB throughout the climatology, especially at higher latitudes.

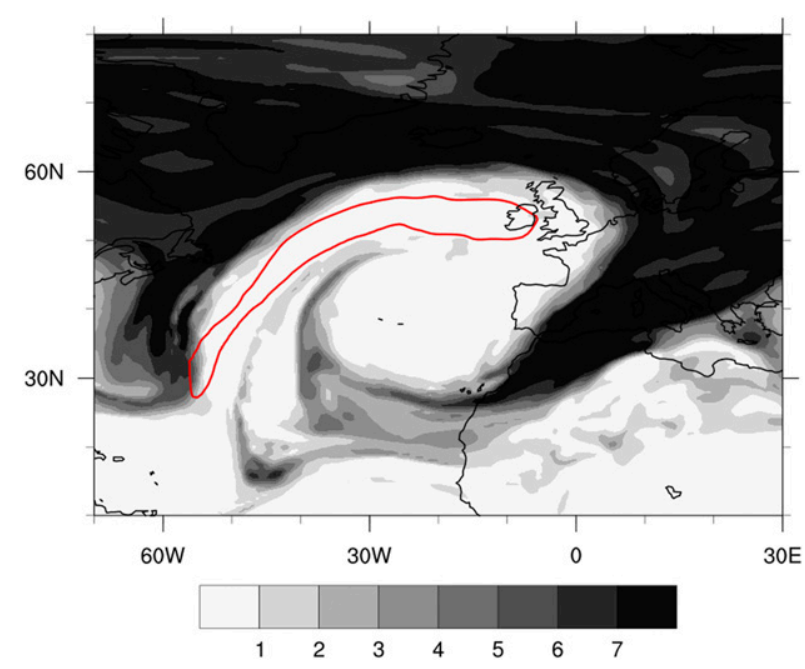

FIG. 3. Example of the spatial positioning of an AR (outlined by the red contour) at 18 UTC 14 Dec 1982 relative to a collocated anticyclonic RWB event, which is identified in the PV field (shaded according to the color bar; PVU) by the southwest-northeast orientation of the overturning contours.

Also, as depicted in Fig. 3, the ARs follow the curvature of the PV contours and are nestled behind the overturning contour on the northwestern flank of the anticyclonic RWB event. Last, a common feature among the composites is a strong, low pressure center to the north/ northwest of the AR and a high pressure center to the south/southwest of the AR, a well-documented feature (Payne and Magnusdottir 2014; Ryoo et al. 2015; Mundhenk et al. 2016b; Hu et al. 2017) that facilitates the development of strong, southwesterly winds that direct the AR toward the coast.

Upon separating ARs that are collocated with anticyclonic RWB from those that are not, minor but important differences in the surrounding environment are observed. The clearest of those differences can be, as expected, observed in PV field. While those composites that contain ARs with anticyclonic RWB (Figs. 4e-h and $5 \mathrm{~d}-\mathrm{f}$ ) depict clear PV contour overturning, those without anticyclonic RWB (Figs. $4 \mathrm{i}-1$ and $5 \mathrm{~g}-\mathrm{i}$ ) depict more zonal PV contours. These differences in PV contour orientation produce a dynamical effect on AR structure, as the ARs tend to follow the path of their surrounding PV contours. Therefore, ARs without anticyclonic RWB possess a more zonal structure, following the zonally oriented PV contours into the coast. Conversely, as found in Payne and Magnusdottir (2014), Ryoo et al. (2015), and Mundhenk et al. (2016b), ARs with anticyclonic RWB have structures that are more northeast-southwest oriented due to the more tilted contours associated with anticyclonically overturning PV. Another difference that arises between the two sets 

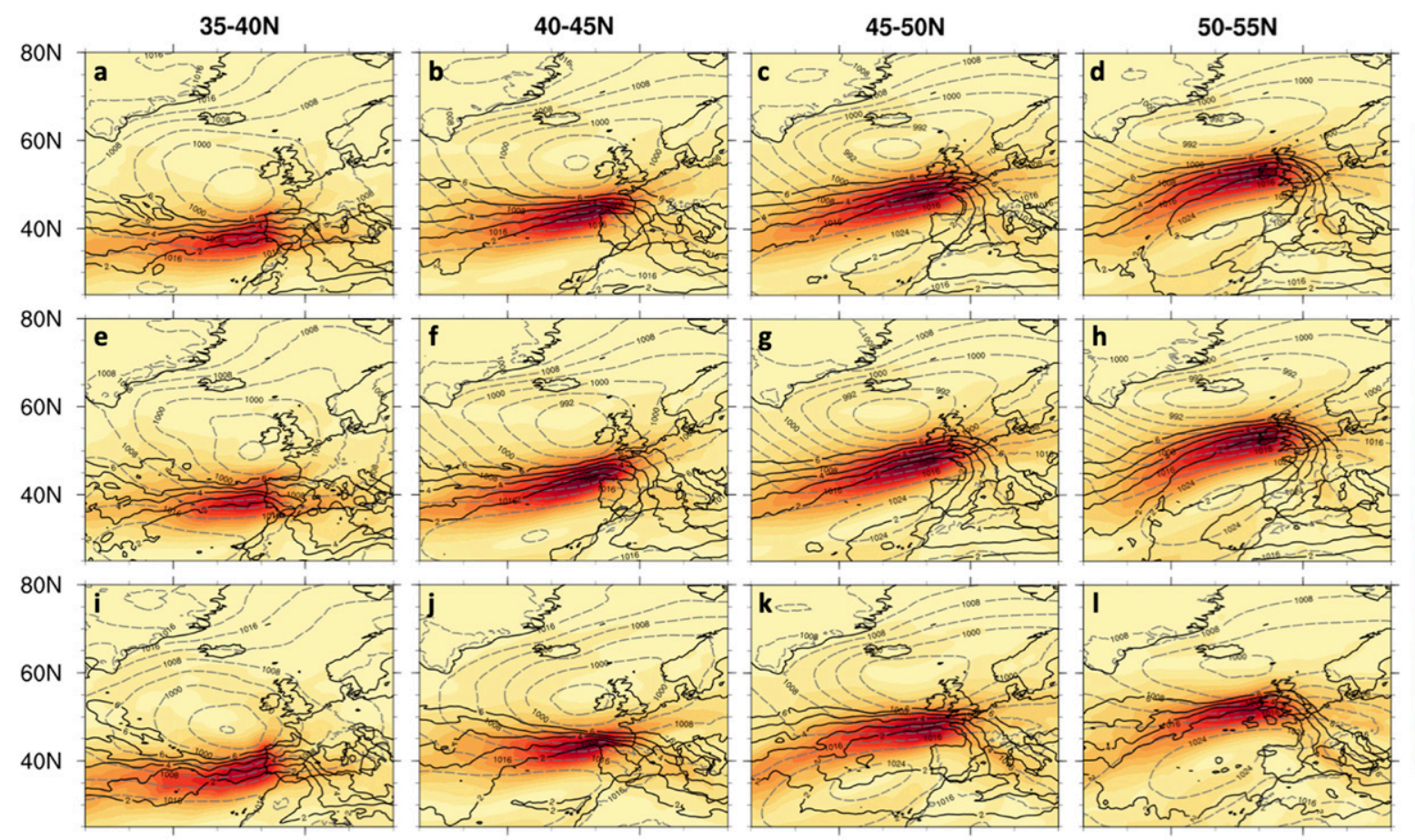

$30 \mathrm{~W}$

0

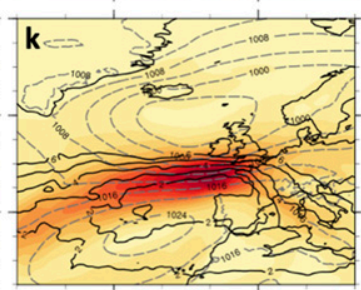

$30 \mathrm{~W}$

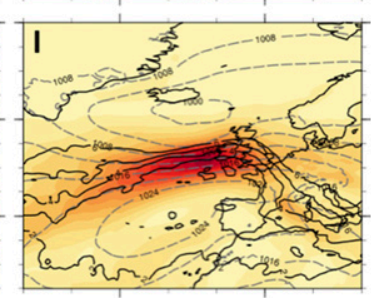

$30 \mathrm{~W}$

0

FIG. 4. Composites of IVT (shaded according to the colorbar; $\mathrm{kg} \mathrm{m}^{-1} \mathrm{~s}^{-1}$ ), SLP (gray dashed contours; hPa), and 200-hPa PV (black contours; PVU) for (a)-(d) all identified ARs, (e)-(h) ARs collocated with anticyclonic RWB, and (i)-(1) ARs without anticyclonic RWB from $35^{\circ}$ to $55^{\circ} \mathrm{N}$ separated by $5^{\circ}$ latitude bin.

of composites can be found in the SLP field. Consistent with the findings in Payne and Magnusdottir (2014) and Mundhenk et al. (2016b), the ARs collocated with anticyclonic RWB tend to have a deeper low to the north/ northwest than those that are not, helping to facilitate stronger low-level winds and, in some cases, stronger ARs. These differences can be seen most clearly in the $40^{\circ}-60^{\circ} \mathrm{N}$ range.

Breaking down the AR-RWB analysis in Fig. 2 by $5^{\circ}$ latitude bin reveals an interesting positive correlation in the data: as latitude increases, so does the percent of ARs collocated with anticyclonic RWB, a trend comparable to results from Ryoo et al. (2015) and Hu et al. (2017). This correlation can be explained by considering two key relationships between RWB and the position of the jet stream. First, anticyclonic RWB is favored on the equatorward side of the jet and cyclonic RWB is favored on the poleward side (Thorncroft et al. 1993; Peters and Waugh 1996; Gabriel and Peters 2008). Second, as the jet stream is displaced poleward or equatorward, anticyclonic or cyclonic RWB becomes more common, respectively (Akahori and Yoden 1997; Franzke et al. 2011; Barnes and Hartmann 2012; Ryoo et al. 2013; Liu and Barnes 2015). To visualize how the jet stream associated with AR events evolves with latitude, the method outlined in Woollings et al. (2010) is used to calculate jet-stream latitudes by vertically averaging daily mean zonal winds from 925 to $700 \mathrm{hPa}$ between $60^{\circ} \mathrm{W}$ and $0^{\circ}$, zonally averaging from $15^{\circ}$ to $75^{\circ} \mathrm{N}$, and applying a 10 -day low-pass filter to then find and record the latitude of the maximum westerly wind speed.

In Fig. 6, the mean position of the jet stream for all AR events is compared to the mean position of the jet stream over the 38-yr climatology for each of the $5^{\circ}$ latitude bins. A clear pattern is observed, such that the latitude of the jet stream and the latitude of the associated AR events are generally collocated, save for the $65^{\circ}-70^{\circ} \mathrm{N}$ bin (Fig. $6 \mathrm{~g}$ ). Given the relationships previously stated, the reasoning behind the correlation found in Fig. 2 starts to come together. As the latitude of the $\mathrm{AR}$ events and associated jet stream increases, so does the overall frequency of anticyclonic RWB (Ryoo et al. 2013; Payne and Magnusdottir 2014), thus increasing the number of ARs collocated with anticyclonic RWB with increasing latitude. While the positioning of the jetstream latitude for the $65^{\circ}-70^{\circ} \mathrm{N}$ bin and some of the $60^{\circ}-65^{\circ} \mathrm{N}$ bin does not appear to follow this relationship, the high frequency of ARs collocated with anticyclonic RWB in this region may be caused by another 

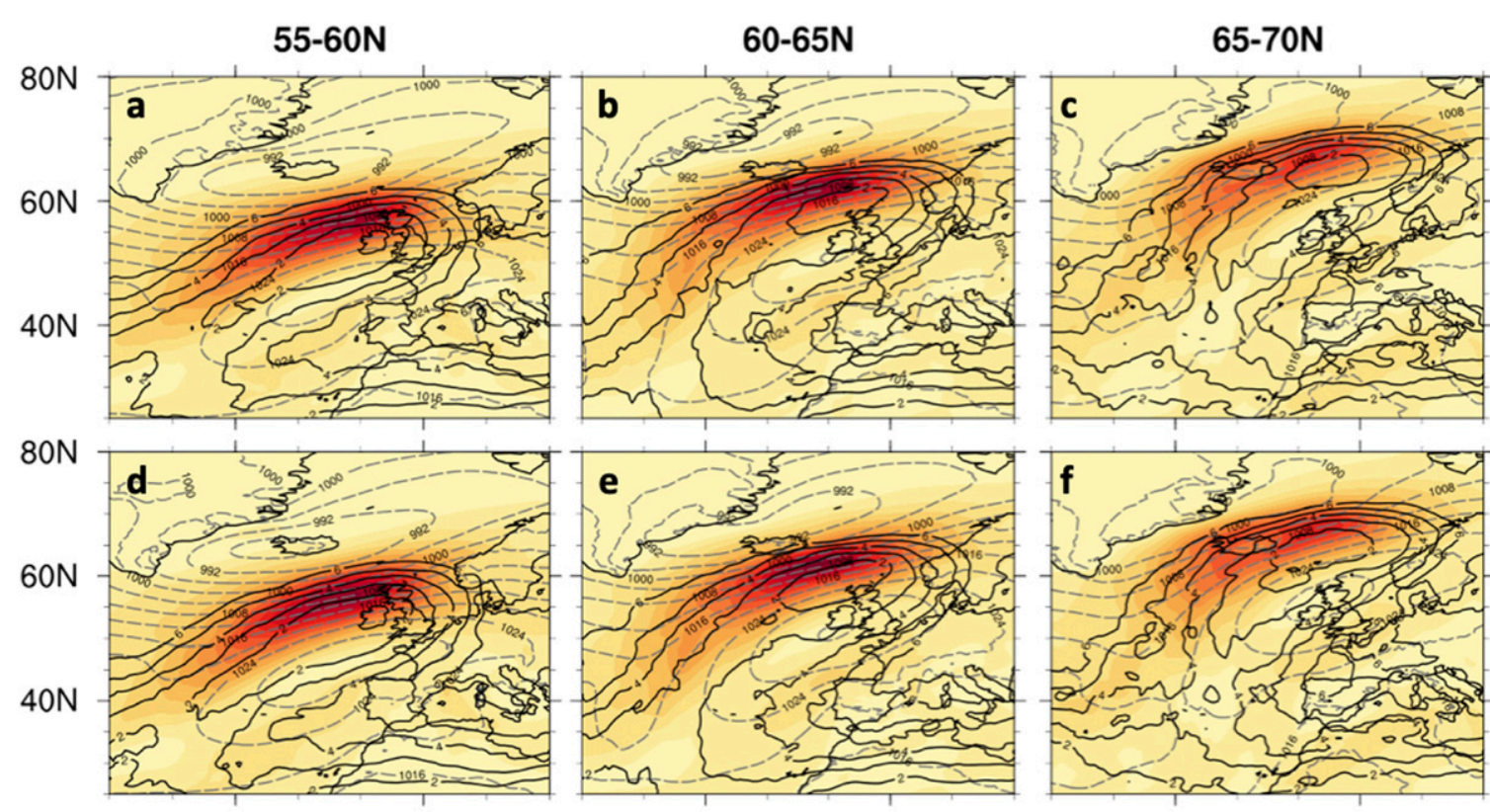

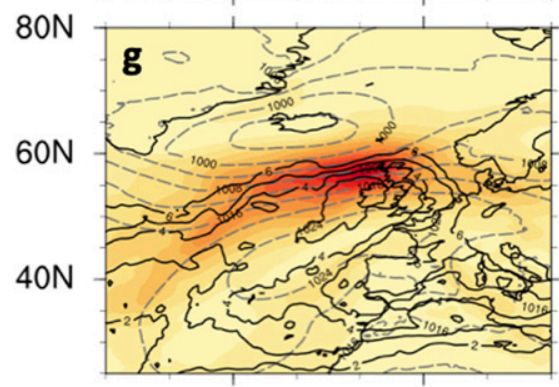

$30 \mathrm{~W}$

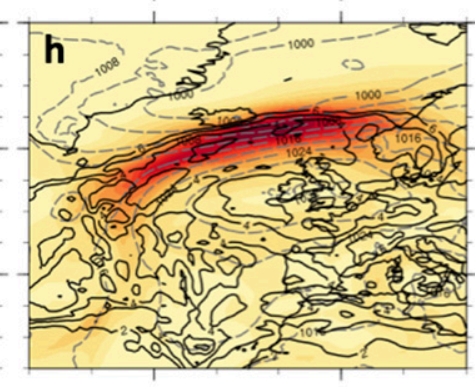

$30 \mathrm{~W}$

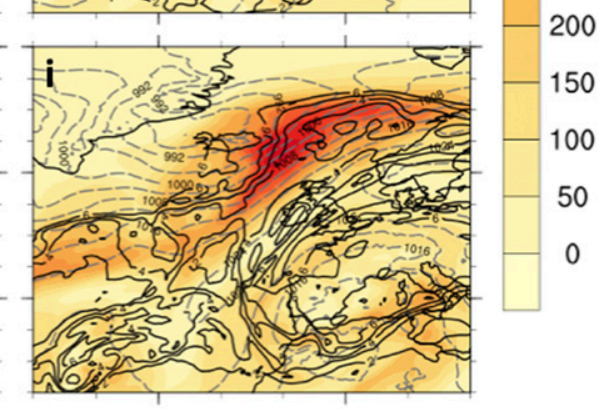

$30 \mathrm{~W}$
700

650

600

550

500

450

400

350

300

250

200

150

100

50

0

FIG. 5. As in Fig. 4 for (a)-(c) all identified ARs, (d)-(f) ARs collocated with anticyclonic RWB, and (g)-(i) ARs without anticyclonic RWB from $55^{\circ}$ to $70^{\circ} \mathrm{N}$ separated by $5^{\circ}$ latitude bin.

mechanism. As illustrated in Michel et al. (2012) and Gómara et al. (2014), anticyclonic RWB over Scandinavia can be stimulated by the northward advection of low PV air by extratropical cyclones over the North Atlantic Ocean, which causes the PV field to deform and subsequently break anticyclonically. Therefore, a combination of jet-stream displacement and extratropical cyclone activity can explain the very high frequency of ARs collocated with anticyclonic RWB at higher latitudes.

Throughout this section, ARs over western Europe have been shown to possess similar large-scale environments, dynamical drivers, and connections to anticyclonic RWB as U.S. West Coast ARs, despite being in two completely separate regions of the globe. With these similarities there also come differences, the largest being the fact that only $3.6 \%$ of ARs in this study were found to be collocated with cyclonic RWB, a percentage slightly lower than the $6.6 \%$ found in Ryoo et al. (2015) and much lower than the approximately $18 \%$ and $25 \%$ found in Mundhenk et al. (2016b) and Hu et al. (2017), respectively. The reasoning for these discrepancies can be explained primarily by differences between the North Pacific and North Atlantic jet streams as well as restricted areas/seasons of focus in the studies by Mundhenk et al. (2016b) and Hu et al. (2017). Over the course of the year, the latitude of the North Pacific jet varies between approximately $35^{\circ}$ and $40^{\circ} \mathrm{N}$ (Mundhenk et al. 2016a), whereas the North Atlantic jet, according to Fig. 6, hovers around $50^{\circ} \mathrm{N}$ year-round. This considerable southerly displacement of the North Pacific jetstream results in much more frequent occurrences of cyclonic RWB over the North Pacific and the U.S. West Coast, especially during El Niño years when the jet is shifted south (Ryoo et al. 2013; Liu et al. 2014), than over the North Atlantic and western Europe. Additionally, by defining their "U.S. West Coast" area of study on the coastline between $35^{\circ}$ 

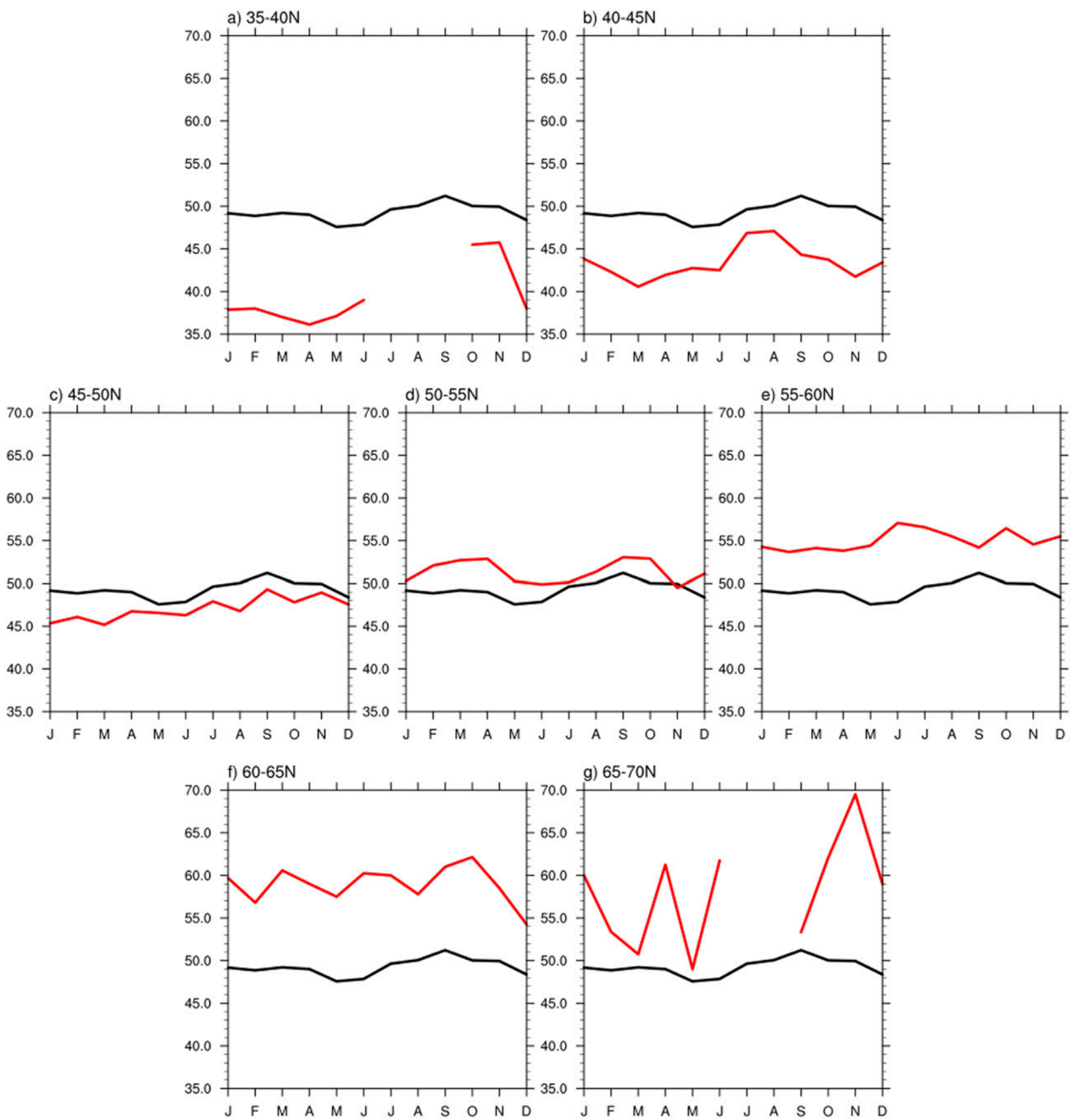

FIG. 6. Comparison of the mean latitude of the climatological jet stream (black) with the mean latitude of the jet stream for all AR events in each $5^{\circ}$ latitude bin (red).

and $45^{\circ} \mathrm{N}$, Mundhenk et al. (2016b) missed out on detecting AR events farther up the coast, of which a large portion would likely have been collocated with anticyclonic RWB, thereby decreasing the cyclonic RWB percentage. The study of Hu et al. (2017) only focuses on ARs during the extended winter (OctoberMarch), the period in which the Pacific jet stream is at its most southerly extent and thus produces an environment that is much more favorable for cyclonic RWB than anticyclonic RWB.

\section{b. Landfalling variability}

As demonstrated in the previous subsection, jetstream latitude is an important factor in determining where an AR will make landfall and can prove useful in predicting where an AR will strike over western Europe. 

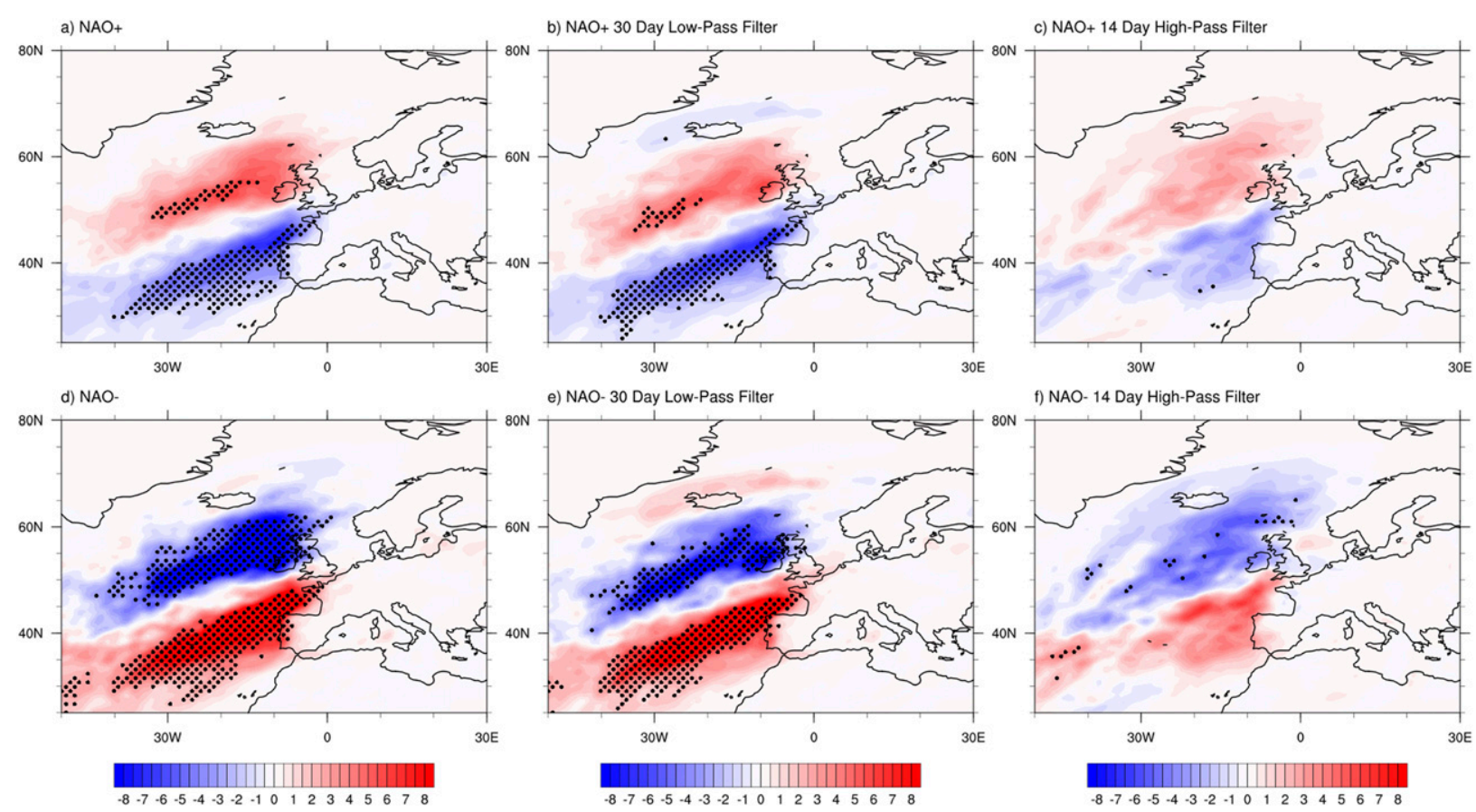

e) NAO- 30 Day Low-Pass Filter
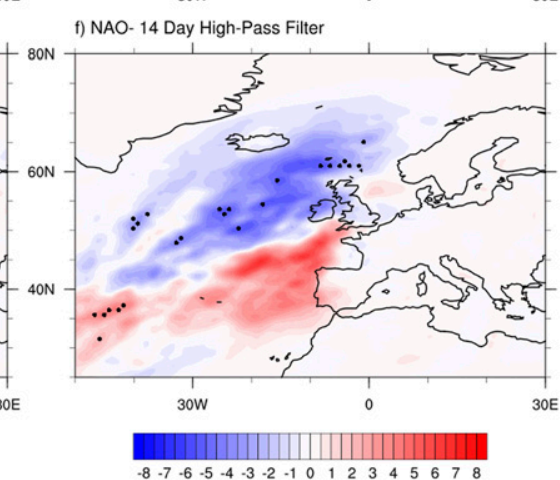

FIG. 7. Difference in AR frequency from the climatology (shaded according to the color bar; \%) during (a) positive NAO (NAO+) and (d) negative NAO (NAO-) and as in (a) and (d) but with a (b),(e) 30-day low-pass filter and (c),(f) 2-week high-pass filter applied to the NAO index. Stippling indicates regions where frequency differences are statistically significant at the $90 \%$ confidence level.

Studies by Hurrell (1995) and Hurrell et al. (2003) have shown that the NAO is a heavy modulator of jet-stream latitude and, as noted in the introduction, AR variability over western Europe. This strong influence of the NAO on AR variability is corroborated in Figs. $7 \mathrm{a}$ and $7 \mathrm{~d}$, which depict the difference in AR frequency from the climatology over western Europe during positive and negative NAO regimes, respectively, where the NAO index used was retrieved from the National Oceanic and Atmospheric Administration's (NOAA's) Climate Prediction Center website data archive and is calculated using the method outlined in Barnston and Livezey (1987). When the NAO is in its positive phase, AR frequency respectively increases and decreases over northern and southern Europe by around $5 \%-6 \%$; during a negative NAO, AR frequency respectively increases and decreases over southern and northern Europe by up to and exceeding $8 \%$. Performing the Student's $t$ test on these differences indicate that they are statistically significant at the $90 \%$ confidence level, especially during the negative NAO. Calculating the difference in AR frequency from the climatology utilizing the EA and SCAND indices (not shown) produced patterns similar to those described in the aforementioned studies. While the EA is shown to induce moderately significant changes in AR frequency, particularly between the Iberian Peninsula and Great Britain during its negative phase, the SCAND produces very weak, insignificant effects on AR frequency.
Overall, as demonstrated by Brands et al. (2017), the NAO is found to have the strongest and most significant impact on AR variability over western Europe.

A larger change in AR frequency is likely observed during negative NAO regimes because the positive regime forces environmental conditions closer to the climatological mean state than the negative regime. Therefore, the negative NAO produces a highly anomalous environment that forces a greater change in AR distribution than the positive NAO relative to climatology. To see whether it is the high- or low-frequency NAO signal that drives the AR frequency changes over western Europe the most, the difference in AR frequency from the climatology during both NAO regimes is recalculated using a 30-day low-pass-filtered (Figs. 7b,e) and 2-week high-pass-filtered (Figs. 7c,f) NAO index. Results from the filtering indicate that the low-frequency part of the NAO signal has an impact that is larger by a factor of 2-3 than the impact of the high-frequency part of the NAO signal on AR frequency modulation over western Europe. This indicates that persistent changes to the synoptic environment brought on by a long-lasting phase of the NAO force a more significant change on AR distribution than do quick changes to the environment produced by short-lived NAO phases, suggesting the potential for AR predictability on subseasonal-tomonthly time scales. 
In general, the dynamic drivers behind AR landfalling variability over western Europe, discussed throughout this section, and the U.S. West Coast are almost identical. Variability in both regions is modulated by climate modes that change the synoptic environment via shifts in the jet stream, which augments the environmental favorability for different types of RWB and shifts the latitude at which the ARs more frequently make landfall. Over western Europe, variability is driven by different phases of the NAO: during a positive NAO the North Atlantic jet is shifted north, creating an environment that is more favorable for anticyclonic RWB and AR landfalls at higher latitudes, and during a negative NAO the jet is shifted south, creating such an environment at lower latitudes. Similarly, over the U.S. West Coast, variability is driven by different phases of the El Niño-Southern Oscillation: during an El Niño the North Pacific jet is shifted south, creating an environment that is favorable for cyclonic RWB and eastward AR trajectories into the southern coastline, and during a $\mathrm{La}$ Niña the North Pacific jet is shifted north, creating an environment that is favorable for anticyclonic RWB and northeastward AR trajectories into the northern coastline. These parallels further stress the notion established in the introduction that ARs in different regions of the world are not unique from one another.

\section{Linear regression analysis}

Figure 7 shows that, based on low-frequency NAO modulation, western European ARs can be cleanly separated into two different subgroups: those in the southern half of the domain from $35^{\circ}$ to $50^{\circ} \mathrm{N}$ and those in the northern half of the domain from $50^{\circ}$ to $70^{\circ} \mathrm{N}$. While knowing what large-scale forces govern the location of landfalling ARs is important, having a comprehensive depiction of the synoptic environment surrounding ARs in these different subgroups is integral to understanding what controls how they develop and how strong their impacts will be upon landfall. To get a clearer view of the atmospheric and oceanic conditions during ARs, linear regression analysis is performed on a pair of AR time series separated by latitude into the northern and southern subgroups. The first time series, AR-S, covers ARs detected between $35^{\circ}$ and $50^{\circ} \mathrm{N}$, and the second group, AR-N, covers ARs detected between $50^{\circ}$ and $70^{\circ} \mathrm{N}$. The time series are constructed by averaging the IVT for each AR event over an area that extends from $30^{\circ} \mathrm{W}$ to $10^{\circ} \mathrm{E}$ and $5^{\circ}$ to the north and south of the central latitude of the $5^{\circ}$ latitude bin where the maximum IVT on the $10^{\circ} \mathrm{W}$ meridian is detected. For example, if the maximum IVT for a particular AR event is detected at $41^{\circ} \mathrm{N}$, the IVT averaged from $30^{\circ} \mathrm{W}$ to $10^{\circ} \mathrm{E}$ and from $37.5^{\circ}$ to $47.5^{\circ} \mathrm{N}$ will be recorded into the time series. Once constructed, the time series are run through a 30-day low-pass filter, given that persistent, low-frequency environmental conditions have a greater impact on ARs than high-frequency conditions, as demonstrated in Fig. 7.

\section{a. Subgroup characteristics}

Composite anomalies of 200-hPa zonal (Figs. 8a,b) and meridional (Figs. 8c,d) winds calculated from the daily climatology and linearly regressed onto the two time series are shown in Fig. 8. AR-N zonal wind anomalies (Fig. 8a) depict a northerly displaced jet centered around $60^{\circ} \mathrm{N}$, while the AR-S (Fig. 8b) jet is located closer to the climatological mean around $45^{\circ} \mathrm{N}$, consistent with the results observed in both Figs. 6 and 7 . In contrast to their zonal wind counterparts, the meridional wind anomalies between the two subgroups greatly differ, painting two unique pictures for each region. AR-N meridional wind anomalies (Fig. 8c) very clearly depict a Rossby wave train extending from the western United States all the way across the North Atlantic to Europe. Given that Rossby wave trains serve as the precursor to the anticyclonic RWB that accompanies $81 \%$ of ARs in the northern subgroup, this result reinforces the idea that ARs at high latitudes have a significant relationship to anticyclonic RWB. As for the meridional anomalies associated with the AR-S subgroup (Fig. 8d), no clear Rossby wave train is present likely due to the lower overall percentage of $A R$ and anticyclonic RWB collocation, however, a quadrupole signal is observed centered off the coast of Spain. The southern half of the quadrupole contains the anticyclonic circulation that drives the ARs, while the northern half contains a strong cyclonic circulation that is perhaps related to circulation anomalies driven by the negative phase of the NAO.

While the dynamical aspects of ARs are important for understanding their features and landfall location variability, obtaining a bigger picture of AR thermodynamics is useful for understanding their intensities and overall impacts. To get a grasp on the thermodynamics behind AR development and intensity, Fig. 9 contains composite anomalies of IVT (Figs. 9a,b) and IWV (Figs. 9c,d), calculated from the daily climatology and linearly regressed onto the two time series. IWV, a quantity used to depict air column moisture, is calculated from 1000 to $300 \mathrm{hPa}$ utilizing the following formula from Rutz et al. (2014):

$$
\mathrm{IWV}=\frac{1}{g} \int_{1000}^{300} q d p
$$



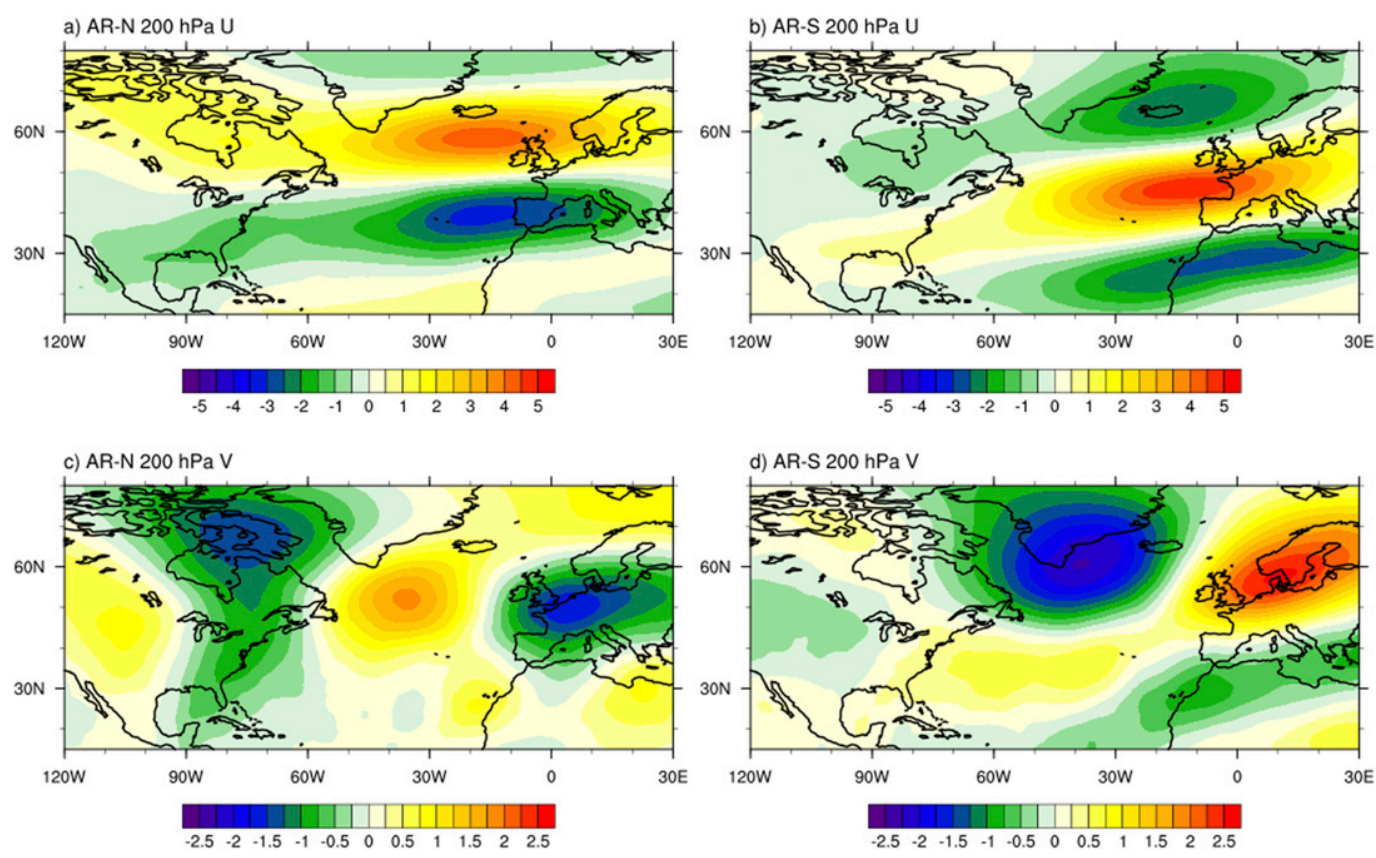

FIG. 8. Composite anomalies of 200-hPa (top) zonal and (bottom) meridional winds (shaded according to the color bar; $\mathrm{m} \mathrm{s}^{-1}$ ) calculated from the daily climatology and linearly regressed onto the (left) AR-N and (right) AR-S time series.

where $g$ is the acceleration due to gravity $\left(\mathrm{m} \mathrm{s}^{-2}\right), q$ is the specific humidity $\left(\mathrm{kg} \mathrm{kg}^{-1}\right)$, and $d p$ is the pressure difference between adjacent pressure levels. The IVT signals (Figs. 9a,b) show clear differences in strength between the two subgroups and, when separated into zonal and meridional components (not shown), are found to be most heavily influenced by the zonal component. Given the breakdown of IVT thresholds in
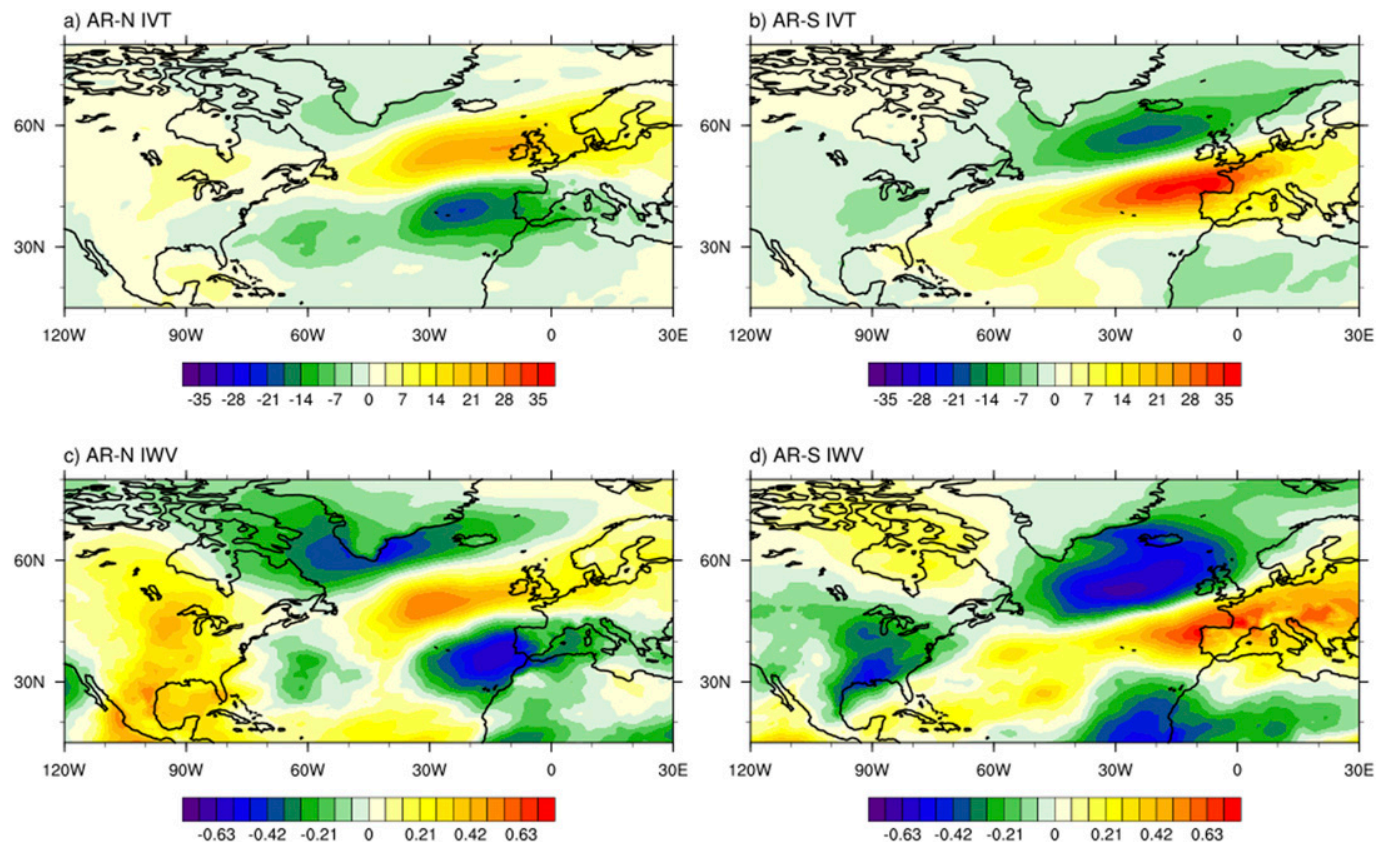

FIG. 9. As in Fig. 8, but for (top) IVT (shaded according to the color bar; $\mathrm{kg} \mathrm{m}^{-1} \mathrm{~s}^{-1}$ ) and (bottom) IWV (shaded according to the color bar; $\mathrm{mm}$ ). 

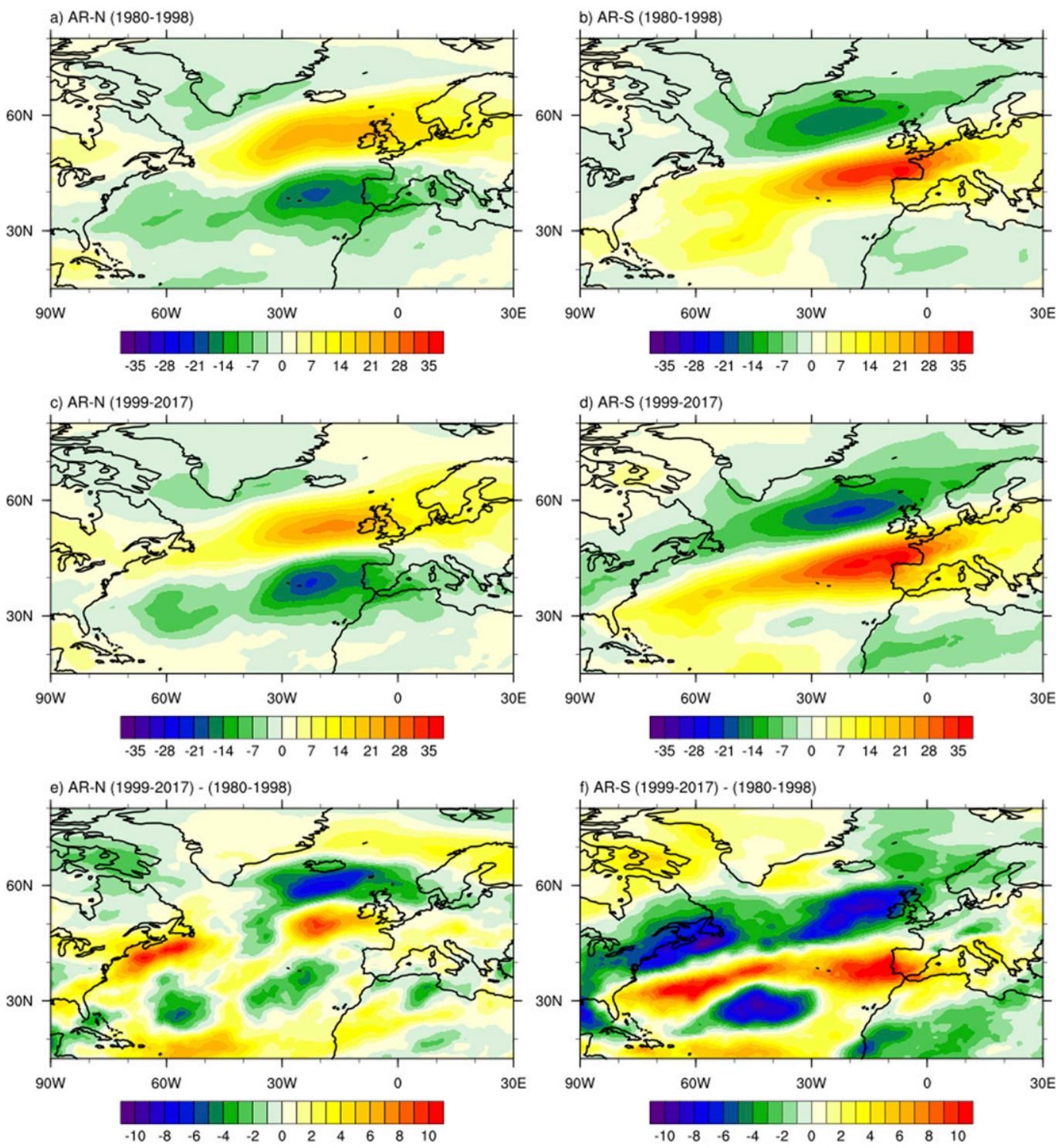

FIG. 10. Composite anomalies of IVT (shaded according to the color bar; $\mathrm{kg} \mathrm{m}^{-1} \mathrm{~s}^{-1}$ ) calculated from the daily climatology and linearly regressed onto the AR-N time series for (a) 1980-98 and (c) 1999-2017 and the AR-S time series for (b) 1980-98 and (d) 1999-2017, as well as differences between the two for (e) AR-N and (f) AR-S.

Table 1, it comes as no surprise that AR-S ARs (Fig. 9b) are more intense than their northern counterparts (Fig. 9a). This disparity can be explained by the higher collocated zonal wind and IWV anomalies observed in the AR-S subgroup (Figs. 8b and 9d) in comparison to AR-N subgroup (Figs. 8a and 9c), particularly near the landfall regions, which, according to Eq. (1), leads to higher IVT values.

\section{b. ARs in a changing climate}

To see whether the predicted changes in IVT and moisture availability described in Dettinger (2011), Lavers et al. (2013), and Warner et al. (2015) are already occurring, linear regressions of anomalous IVT, IWV, and sea surface temperature (SST) for the first and second halves of the climatology, 1980-98 and 19992017, respectively, are calculated and compared to see how the fields have changed over time. SST's used for the regressions are from NOAA's $14^{\circ}$ Optimum Interpolation Sea Surface Temperature dataset (Reynolds et al. 2008). Examination of Fig. 10 shows that between the periods of 1980-98 and 1999-2017 the IVT values for both the AR-N and AR-S groups have undergone a slight increase overall, while the spatial extent of the IVT signals have also changed, though more noticeably in the AR-S subgroup. Throughout the climatology ARs in the AR- 


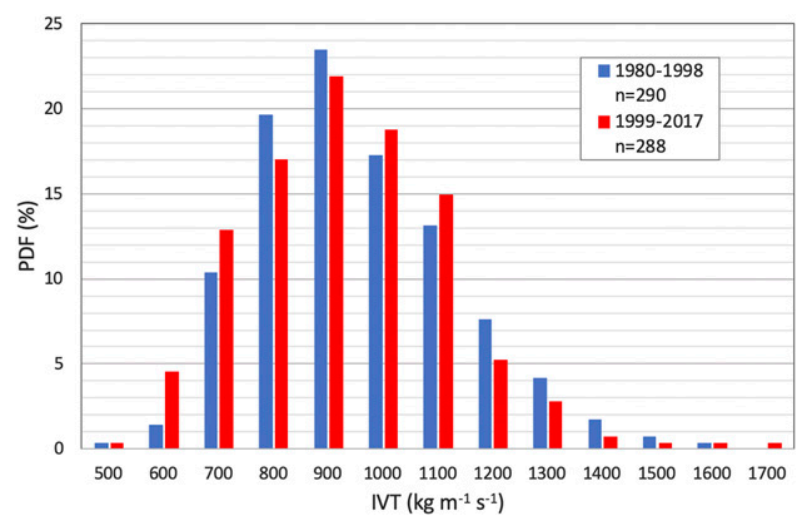

FIG. 11. Probability density functions of the maximum IVT distribution for ARs during the periods of 1980-98 (blue) and 19992017 (red). Equally sized bins of $100 \mathrm{~kg} \mathrm{~m}^{-1} \mathrm{~s}^{-1}$ were used.

$\mathrm{N}$ subgroup have undergone a slight meridional shift, with ARs in the earlier period (Fig. 10a) being located farther north than those in the later period (Fig. 10c). In the AR-S subgroup, IVT signals are shown to have elongated over time, as the tail end of the IVT signals have shifted from the midsubtropical North Atlantic around $40^{\circ} \mathrm{W}$ (Fig. 10b) to farther west around $60^{\circ} \mathrm{W}$. To more clearly see the increase in IVT values over time, probability density functions of the maximum IVT distribution for each period are shown in Fig. 11. According to the figure, while the majority of ARs in the earlier period had a maximum IVT between 800 and $900 \mathrm{~kg} \mathrm{~m}^{-1} \mathrm{~s}^{-1}$, those in the later period had a maximum IVT between 900 and $1000 \mathrm{~kg} \mathrm{~m}^{-1} \mathrm{~s}^{-1}$, indicating a shift toward higher IVT values. A Student's $t$ test is applied to both sets of IVT distributions and a $p$ value of 0.065 is returned, indicating that the observed shift is significant at the $90 \%$ confidence level.

To see if this shift toward higher IVT values is consistent with the conclusions of Dettinger (2011), Lavers et al. (2013), and Warner et al. (2015), attention must be turned to the analysis of the observed change in IWV over time (Fig. 12). In agreement with these studies, the amount of atmospheric moisture available is observed to increase between the periods of 1980-98 and 1999-2017 for both the AR-N (Figs. 12a,c) and AR-S (Figs. 12b,d) subgroups. In the AR-N subgroup the increase is subtle, but discernible in the region of the ARs' moisture source between $40^{\circ}$ and $55^{\circ} \mathrm{N}$ and from $50^{\circ} \mathrm{W}$ to the European coastline. In contrast to the AR-N subgroup, the differences in IWV between the two periods in the AR-S subgroup are much more robust in two main areas. The first area, near the coastline, shows a more zonally confined yet stronger moisture anomaly available to the ARs in that region in the later period. The second area is the ARs' moisture source region in the subtropics, which shifts from two regions $\left(15^{\circ}-30^{\circ} \mathrm{N}, 55^{\circ}-40^{\circ} \mathrm{W}\right.$ and $35^{\circ}-$ $45^{\circ} \mathrm{N}, 70^{\circ}-50^{\circ} \mathrm{W}$ ) in the earlier period (Fig. $12 \mathrm{~b}$ ) to $20^{\circ}-40^{\circ} \mathrm{N}, 80^{\circ}-50^{\circ} \mathrm{W}$ in the later period (Fig. 12d). Comparing these regions with one another reveals that the moisture anomalies in the later period are much stronger than those in the earlier period, contributing to the increased IVT values observed in Fig. 10d. To ascertain the robustness of these IVT and IWV signal changes over time, for each field two subsets from each period are taken, four in total, and compared with one another. Analysis of these subsets (not shown) is consistent in showing that ARs in both subgroups generally have higher IVT and IWV values in the later period, indicating a strengthening of ARs over time.

In an effort to answer the question of why both the IVT values and moisture availabilities shift spatially and increase in magnitude over time, it is helpful to analyze how the SST anomalies also changed between the two periods (Fig. 13). Features that stick out right away are the overall stronger positive SST anomalies in the ARs' moisture source regions for both subgroups in the later period (Figs. 13c,d) relative to those in the earlier period (Figs. 13a,b). This increase in positive SST anomalies over time, although small, is consistent with the increase in the amount of atmospheric moisture available observed in Fig. 12. Additionally, the western shift in the positive SST anomalies observed in the AR-S subgroup from the earlier to the later period could explain the shifts in the tail end of the IVT signals and the AR moisture source regions from the mid(sub)tropical North Atlantic to the western (sub)tropical North Atlantic between periods, as observed in Figs. 10b, 10d, $12 \mathrm{~b}$, and $12 \mathrm{~d}$, respectively. These results suggest that positive SST anomalies, however small, can play an important role in modulating where and how much atmospheric moisture is available and, by extension, where an AR first develops and how intense it can become.

\section{Summary and conclusions}

This study has investigated how landfalling ARs over western Europe are modulated from both dynamic and thermodynamic perspectives, with an initial primary focus on RWB. In doing so, 38 years of the MERRA-2 reanalysis dataset are utilized to develop an AR climatology, which is compiled employing the AR detection algorithm outlined in Lavers and Villarini (2013). Over the course of the climatology a total of 578 ARs were identified, and, consistent with previous studies, the most frequent ARs with the highest IVT values were found from $45^{\circ}$ to $55^{\circ} \mathrm{N}$. Following the development of the AR climatology, 200-hPa PV fields surrounding each AR are scanned for the presence of an RWB event with 

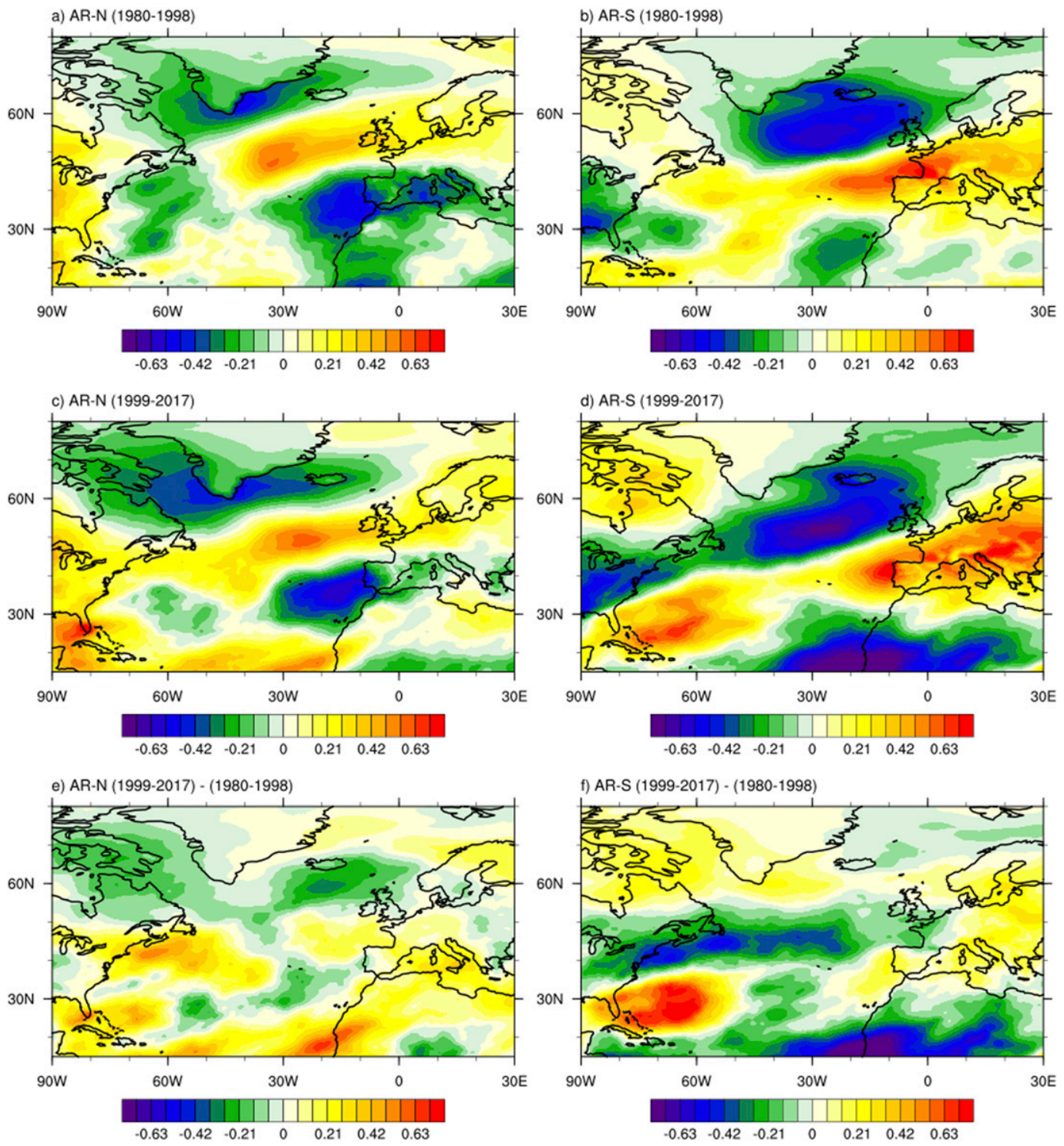

FIG. 12. As in Fig. 10, but for IWV (shaded according to the color bar; mm).

the purpose of ascertaining whether or not a relationship exists between ARs and RWB.

Using similar methods to those described in Zavadoff and Kirtman (2019) and Payne and Magnusdottir (2014), the state of the PV fields around each AR are classified into three groups: anticyclonic RWB, cyclonic RWB, and unlabeled other. The results of this analysis show that of the 578 landfalling ARs detected, 423, or approximately $73 \%$, were found to be collocated with anticyclonic RWB, positioned behind the overturning high-PV tongue on northwestward flank of the RWB event. Of the remaining 155 ARs detected, only 22 were found to be related to cyclonic RWB, while the rest fell into the category of other. Composite analysis of IVT, SLP, and 200-hPa PV comparing ARs collocated with anticyclonic RWB to those without anticyclonic RWB revealed that ARs are structured in a manner that mimics the path of their surrounding PV contours. As such, ARs collocated with anticyclonic RWB exhibit more northeast-southwest-oriented structures because of the tilted overturning PV contours nearby, while those ARs without anticyclonic RWB possess a more zonal structure, following the zonally oriented PV contours into the coast. In addition, ARs collocated with anticyclonic RWB are observed to have a deeper low to the north/northwest than those that are not, helping to facilitate stronger low-level winds and, in some cases, stronger ARs. 

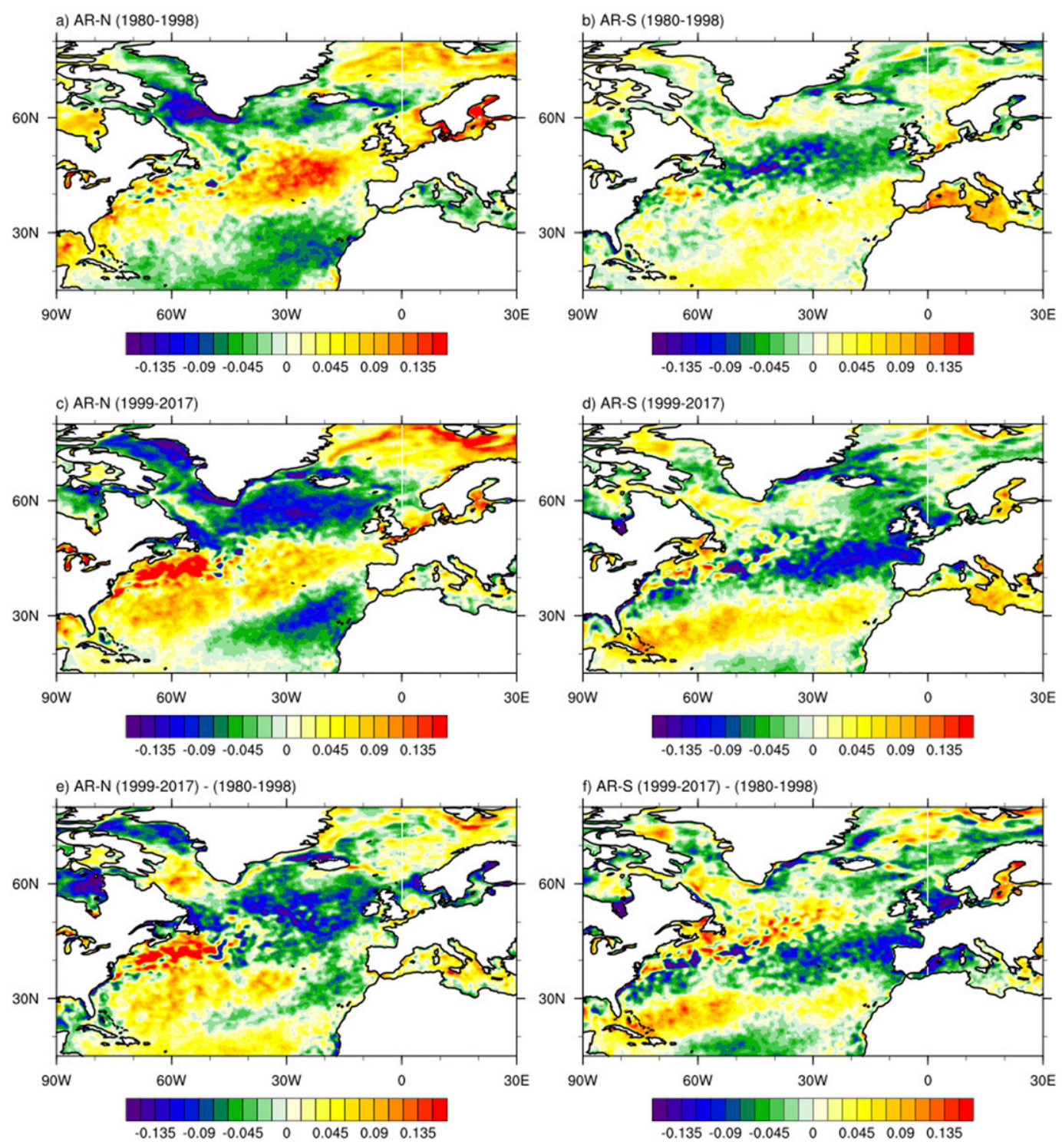

FIG. 13. As in Fig. 10, but for SST (shaded according to the color bar; K).

A deeper look into the relationship between ARs and RWB shows a positive correlation between latitude and the percent of ARs collocated with anticyclonic RWB. This is explained by the fact that anticyclonic RWB is favored on the equatorward side of the jet, as the jet stream is displaced poleward anticyclonic RWB becomes more common, and that throughout the study domain, the latitude of the jet stream and the latitude of the associated AR events are generally collocated. Therefore, with an increase in the latitude of the observed ARs there is an increase in the overall frequency of anticyclonic RWB, thus increasing the number of ARs collocated with anticyclonic RWB. In agreement with the findings in Lavers and Villarini (2013) and
Brands et al. (2017), results indicate that, depending on the phase of the NAO, AR frequency over some parts of western Europe can change by up to and exceeding $8 \%$, which is mostly attributable to the low-frequency part of the overall NAO signal. This is because when the NAO is positive the North Atlantic jet is shifted north, creating an environment more favorable for anticyclonic RWB and AR landfalls over northern Europe, and when the NAO is negative the North Atlantic jet is shifted south, creating such an environment over southern Europe.

In addition to knowing what large-scale forces govern the location of landfalling ARs, having a comprehensive depiction of the synoptic environment surrounding ARs is integral to understanding what controls their development 
and intensities. To get a clearer view of the atmospheric and oceanic conditions during ARs, linear regression analysis is performed on a pair of low-frequency AR time series separated by latitude into the northern and southern subgroups. Composite anomalies of $200-\mathrm{hPa}$ zonal and meridional winds, IVT, and IWV are analyzed, showing clearly that ARs in the AR-S subgroup are stronger than those in the AR-N subgroup. This is due to ARs in the AR-S group having higher collocated zonal wind and IWV anomalies than ARs in the AR-N group, which, according to the IVT equation, leads to higher IVT values and more intense ARs. To see how the strength of ARs will change in a changing climate, linear regressions of IVT, IWV, and SST of the first and last halves of the climatology, 1980-98 and 1999-2017, respectively, are calculated and compared to see how they changed over time. Consistent with the findings of Dettinger (2011), Lavers et al. (2013), and Warner et al. (2015), results indicate that strength of ARs has increased throughout the climatology, with ARs in the earlier period exhibiting IVT maxima primarily in the $800-900 \mathrm{~kg} \mathrm{~m}^{-1} \mathrm{~s}^{-1}$ range, whereas IVT maxima in the later period increased to be primarily in the 900 $1000 \mathrm{~kg} \mathrm{~m}^{-1} \mathrm{~s}^{-1}$ range. This is due to an increase in the amount of atmospheric moisture available in the ARs' moisture source regions between the periods of 1980-98 and 1999-2017, which likely can be attributed to an increase in positive SST anomalies in the ARs' moisture source regions over time, suggesting that positive SST anomalies play a role in modulating atmospheric moisture availability and, by extension, AR development and intensity.

These results indicate that ARs are heavily modulated by both dynamic and thermodynamic forces. Most importantly, uncovering the AR-RWB relationship in Europe and confirming that it exists in multiple parts of the world (not just along the U.S. West Coast) suggests that it could exist anywhere ARs can be found, opening the door to a greater understanding of what governs AR motion and structure worldwide. In addition, this connection can be useful for AR prediction, which can prove valuable given the extreme impacts of ARs on wherever they occur. Using jet-stream latitude and forecast models to determine where and when anticyclonic RWB events may happen combined with atmospheric moisture content fields, one can reasonably predict whether an AR will or will not form and, if it does, where it will have the greatest impact.

Acknowledgments. The authors thank the National Oceanic and Atmospheric Administration for their support under Grants NA160AR4310141, NA160AR4310149, and NA150AR4320064. We also acknowledge the three anonymous reviewers for their constructive and valuable feedback that served to considerably improve this paper, the University of Miami Center for Computational Science for providing indispensable computational resources, and the NASA Goddard Earth Sciences Data and Information Services Center for access to the MERRA-2 reanalysis dataset.

\section{REFERENCES}

Akahori, K., and S. Yoden, 1997: Zonal flow vacillation and bimodality of baroclinic eddy life cycles in a simple global circulation model. J. Atmos. Sci., 54, 2349-2361, https://doi.org/ 10.1175/1520-0469(1997)054<2349:ZFVABO>2.0.CO;2.

Bao, J., S. Michelson, P. Neiman, F. Ralph, and J. Wilczak, 2006: Interpretation of enhanced integrated water vapor bands associated with extratropical cyclones: Their formation and connection to tropical moisture. Mon. Wea. Rev., 134, 10631080, https://doi.org/10.1175/MWR3123.1.

Barnes, E. A., and D. L. Hartmann, 2012: Detection of Rossby wave breaking and its response to shifts of the midlatitude jet with climate change. J. Geophys. Res., 117, D09117, https:// doi.org/10.1029/2012JD017469.

Barnston, A. G., and R. E. Livezey, 1987: Classification, seasonality and persistence of low-frequency atmospheric circulation patterns. Mon. Wea. Rev., 115, 1083-1126, https://doi.org/ 10.1175/1520-0493(1987)115<1083:CSAPOL > 2.0.CO;2.

Brands, S., J. M. Gutiérrez, and D. San-Martín, 2017: Twentiethcentury atmospheric river activity along the west coasts of Europe and North America: Algorithm formulation, reanalysis uncertainty and links to atmospheric circulation patterns. Climate Dyn., 48, 2771-2795, https://doi.org/10.1007/ s00382-016-3095-6.

Debbage, N., P. Miller, S. Poore, K. Morano, T. Mote, and J. M. Shepherd, 2017: A climatology of atmospheric river interactions with the southeastern United States coastline. Int. J. Climatol., 37, 4077-4091, https://doi.org/10.1002/ joc. 5000

Dettinger, M., 2011: Climate change, atmospheric rivers, and floods in California-A multimodel analysis of storm frequency and magnitude changes. J. Amer. Water Resour. Assoc., 47, 514523, https://doi.org/10.1111/j.1752-1688.2011.00546.x.

_ 2013: Atmospheric rivers as drought busters on the U.S. West Coast. J. Hydrometeor., 14, 1721-1732, https://doi.org/10.1175/ JHM-D-13-02.1.

Eiras-Barca, J., F. Dominguez, H. Hu, D. Garaboa-Paz, and G. Miguez-Macho, 2017: Evaluation of the moisture sources in two extreme landfalling atmospheric river events using an Eulerian WRF tracers tool. Earth Syst. Dyn., 8, 1247-1261, https://doi.org/10.5194/esd-8-1247-2017.

Fragoso, M., R. M. Trigo, J. L. Zêzere, and M. A. Valente, 2010: The exceptional rainfall event in Lisbon on 18 February 2008. Weather, 65, 31-35, https://doi.org/10.1002/wea.513.

Franzke, C., T. Woollings, and O. Martius, 2011: Persistent circulation regimes and preferred regime transitions in the North Atlantic. J. Atmos. Sci., 68, 2809-2825, https://doi.org/10.1175/ JAS-D-11-046.1.

Gabriel, A., and D. Peters, 2008: A diagnostic study of different types of Rossby wave breaking events in the northern extratropics. J. Meteor. Soc. Japan, 86, 613-631, https://doi.org/ 10.2151/jmsj.86.613. 
Gelaro, R., and Coauthors, 2017: The Modern-Era Retrospective Analysis for Research and Applications, version 2 (MERRA-2). J. Climate, 30, 5419-5454, https://doi.org/10.1175/JCLI-D16-0758.1.

Gómara, I., J. G. Pinto, T. Woollings, G. Masato, P. Zurita-Gotor, and B. Rodríguez-Fonseca, 2014: Rossby wave-breaking analysis of explosive cyclones in the Euro-Atlantic sector. Quart. J. Roy. Meteor. Soc., 140, 738-753, https://doi.org/10.1002/qj.2190.

Guan, B., and D. E. Waliser, 2015: Detection of atmospheric rivers: Evaluation and application of an algorithm for global studies. J. Geophys. Res. Atmos., 120, 12 514-12 535, https://doi.org/ 10.1002/2015JD024257.

Higgins, R., J. E. Schemm, W. Shi, and A. Leetmaa, 2000: Extreme precipitation events in the western United States related to tropical forcing. J. Climate, 13, 793-820, https://doi.org/10.1175/ 1520-0442(2000)013<0793:EPEITW > 2.0.CO;2.

Hu, H., F. Dominguez, Z. Wang, D. A. Lavers, G. Zhang, and F. M. Ralph, 2017: Linking atmospheric river hydrological impacts on the U.S. West Coast to Rossby wave breaking. J. Climate, 30, 3381-3399, https://doi.org/10.1175/JCLI-D-16-0386.1.

Hurrell, J. W., 1995: Decadal trends in the North Atlantic Oscillation: Regional temperatures and precipitation. Science, 269, 676-679, https://doi.org/10.1126/science.269.5224.676.

—, Y. Kushnir, G. Ottersen, and M. Visbeck, 2003: An overview of the North Atlantic Oscillation. The North Atlantic Oscillation: Climatic Significance and Environmental Impact, Geophys. Monogr., Vol. 134, Amer. Geophys. Union, 1-36.

Knippertz, P., and H. Wernli, 2010: A Lagrangian climatology of tropical moisture exports to the Northern Hemispheric extratropics. J. Climate, 23, 987-1003, https://doi.org/10.1175/ 2009JCLI3333.1.

,$- \ldots$, and G. Gläser, 2013: A global climatology of tropical moisture exports. J. Climate, 26, 3031-3045, https://doi.org/ 10.1175/JCLI-D-12-00401.1.

Lackmann, G. M., and J. R. Gyakum, 1999: Heavy cold-season precipitation in the northwestern United States: Synoptic climatology and an analysis of the flood of 17-18 January 1986. Wea. Forecasting, 14, 687-700, https://doi.org/10.1175/15200434(1999)014<0687:HCSPIT>2.0.CO;2.

Lavers, D. A., and G. Villarini, 2013: The nexus between atmospheric rivers and extreme precipitation across Europe. Geophys. Res. Lett., 40, 3259-3264, https://doi.org/10.1002/grl.50636.

- , and — 2015: The contribution of atmospheric rivers to precipitation in Europe and the United States. J. Hydrol., 522, 382-390, https://doi.org/10.1016/j.jhydrol.2014.12.010.

— R. P. Allan, E. F. Wood, G. Villarini, D. J. Brayshaw, and A. J. Wade, 2011: Winter floods in Britain are connected to atmospheric rivers. Geophys. Res. Lett., 38, L23803, https:// doi.org/10.1029/2011GL049783.

, G. Villarini, R. P. Allan, E. F. Wood, and A. J. Wade, 2012: The detection of atmospheric rivers in atmospheric reanalyses and their links to British winter floods and the large-scale climatic circulation. J. Geophys. Res., 117, D20106, https:// doi.org/10.1029/2012JD018027.

- R. P. Allan, G. Villarini, B. Lloyd-Hughes, D. J. Brayshaw, and A. J. Wade, 2013: Future changes in atmospheric rivers and their implications for winter flooding in Britain. Environ. Res. Lett., 8 , 034010, https://doi.org/10.1088/1748-9326/8/3/034010.

Liberato, M. L., A. M. Ramos, R. M. Trigo, I. F. Trigo, A. M. Durán-Quesada, R. Nieto, and L. Gimeno, 2012: Moisture sources and large-scale dynamics associated with a flash flood event. Lagrangian Modeling of the Atmosphere, Geophys. Monogr., Vol. 200, Amer. Geophys. Union, 111-126.
Liu, C., and E. A. Barnes, 2015: Extreme moisture transport into the Arctic linked to Rossby wave breaking. J. Geophys. Res. Atmos., 120, 3774-3788, https://doi.org/10.1002/2014JD022796.

-, X. Ren, and X. Yang, 2014: Mean flow-storm track relationship and Rossby wave breaking in two types of El-Niño. Adv. Atmos. Sci., 31, 197-210, https://doi.org/10.1007/s00376013-2297-7.

McIntyre, M., and T. Palmer, 1983: Breaking planetary waves in the stratosphere. Nature, 305, 593-600, https://doi.org/10.1038/ $305593 \mathrm{a} 0$.

— and - 1984: The 'surf zone' in the stratosphere. J. Atmos. Terr. Phys., 46, 825-849, https://doi.org/10.1016/0021-9169(84) 90063-1.

Michel, C., G. Rivière, L. Terray, and B. Joly, 2012: The dynamical link between surface cyclones, upper-tropospheric Rossby wave breaking and the life cycle of the Scandinavian blocking. Geophys. Res. Lett., 39, L10806, https://doi.org/ 10.1029/2012GL051682.

Mundhenk, B. D., E. A. Barnes, and E. D. Maloney, 2016a: Allseason climatology and variability of atmospheric river frequencies over the North Pacific. J. Climate, 29, 4885-4903, https://doi.org/10.1175/JCLI-D-15-0655.1.

$\longrightarrow,-,-$, and K. M. Nardi, 2016b: Modulation of atmospheric rivers near Alaska and the U.S. West Coast by northeast Pacific height anomalies. J. Geophys. Res. Atmos, 121, 12 751-12 765, https://doi.org/10.1002/2016JD025350.

Neiman, P. J., F. M. Ralph, G. A. Wick, J. D. Lundquist, and M. D. Dettinger, 2008: Meteorological characteristics and overland precipitation impacts of atmospheric rivers affecting the west coast of North America based on eight years of SSM/I satellite observations. J. Hydrometeor., 9, 22-47, https:// doi.org/10.1175/2007JHM855.1.

— L. J. Schick, F. M. Ralph, M. Hughes, and G. A. Wick, 2011: Flooding in western Washington: The connection to atmospheric rivers. J. Hydrometeor., 12, 1337-1358, https://doi.org/ 10.1175/2011JHM1358.1.

Newell, R. E., N. E. Newell, Y. Zhu, and C. Scott, 1992: Tropospheric rivers?-A pilot study. Geophys. Res. Lett., 19, 2401-2404, https://doi.org/10.1029/92GL02916.

Payne, A. E., and G. Magnusdottir, 2014: Dynamics of landfalling atmospheric rivers over the North Pacific in 30 years of MERRA reanalysis. J. Climate, 27, 7133-7150, https://doi.org/ 10.1175/JCLI-D-14-00034.1.

Peters, D., and D. W. Waugh, 1996: Influence of barotropic shear on the poleward advection of upper-tropospheric air. J. Atmos. Sci., 53, 3013-3031, https://doi.org/10.1175/15200469(1996)053<3013:IOBSOT > 2.0.CO;2.

Postel, G. A., and M. H. Hitchman, 1999: A climatology of Rossby wave breaking along the subtropical tropopause. J. Atmos. Sci., 56, 359-373, https://doi.org/10.1175/1520-0469(1999) $056<0359$ :ACORWB $>2.0$. CO 2

Ralph, F. M., and M. Dettinger, 2011: Storms, floods, and the science of atmospheric rivers. Eos, Trans. Amer. Geophys. Union, 92, 265-266, https://doi.org/10.1029/2011EO320001.

- and - 2012: Historical and national perspectives on extreme West Coast precipitation associated with atmospheric rivers during December 2010. Bull. Amer. Meteor. Soc., 93, 783-790, https://doi.org/10.1175/BAMS-D-11-00188.1.

— P. J. Neiman, and G. A. Wick, 2004: Satellite and CALJET aircraft observations of atmospheric rivers over the eastern North Pacific Ocean during the winter of 1997/98. Mon. Wea Rev., 132, 1721-1745, https://doi.org/10.1175/1520-0493(2004) $132<1721:$ SACAOO $>2.0 . \mathrm{CO} ; 2$ 
, S. I. Gutman, M. D. Dettinger, D. R. Cayan, and A. B. White, 2006: Flooding on California's Russian River: Role of atmospheric rivers. Geophys. Res. Lett., 33, L13801, https://doi.org/10.1029/2006GL026689.

_ , and Coauthors, 2017: Dropsonde observations of total integrated water vapor transport within North Pacific atmospheric rivers. J. Hydrometeor., 18, 2577-2596, https://doi.org/10.1175/ JHM-D-17-0036.1.

Ramos, A. M., R. M. Trigo, M. L. Liberato, and R. Tomé, 2015: Daily precipitation extreme events in the Iberian Peninsula and its association with atmospheric rivers. J. Hydrometeor. 16, 579-597, https://doi.org/10.1175/JHM-D-14-0103.1.

—, R. Nieto, R. Tomé, L. Gimeno, R. M. Trigo, M. L. Liberato, and D. A. Lavers, 2016: Atmospheric rivers moisture sources from a Lagrangian perspective. Earth Syst. Dyn., 7, 371-384, https://doi.org/10.5194/esd-7-371-2016.

Reynolds, R. W., V. F. Banzon, and N. C. Program, 2008: NOAA Optimum Interpolation $1 / 4$ Degree Daily Sea Surface Temperature (OISST) analysis, version 2. NOAA National Climatic Data Center, accessed 20 May 2019, https:// doi.org/10.7289/V5SQ8XB5.

Rienecker, M. M., and Coauthors, 2011: MERRA: NASA's Modern-Era Retrospective Analysis for Research and Applications. J. Climate, 24, 3624-3648, https://doi.org/ 10.1175/JCLI-D-11-00015.1.

Rutz, J. J., W. J. Steenburgh, and F. M. Ralph, 2014: Climatological characteristics of atmospheric rivers and their inland penetration over the western United States. Mon. Wea. Rev., 142, 905-921, https://doi.org/10.1175/MWR-D-13-00168.1.

Ryoo, J.-M., Y. Kaspi, D. W. Waugh, G. N. Kiladis, D. E. Waliser, E. J. Fetzer, and J. Kim, 2013: Impact of Rossby wave breaking on U.S. West Coast winter precipitation during ENSO events. J. Climate, 26, 6360-6382, https://doi.org/10.1175/JCLI-D-12-00297.1.

_, D. E. Waliser, D. W. Waugh, S. Wong, E. J. Fetzer, and I. Fung, 2015: Classification of atmospheric river events on the U.S. West Coast using a trajectory model. J. Geophys. Res. Atmos., 120, 3007-3028, https://doi.org/10.1002/2014JD022023.
Shields, C. A., and Coauthors, 2018: Atmospheric River Tracking Method Intercomparison Project (ARTMIP): Project goals and experimental design. Geosci. Model Dev., 11, 2455-2474, https://doi.org/10.5194/gmd-11-2455-2018.

Sodemann, H., and A. Stohl, 2013: Moisture origin and meridional transport in atmospheric rivers and their association with multiple cyclones. Mon. Wea. Rev., 141, 2850-2868, https:// doi.org/10.1175/MWR-D-12-00256.1.

Thorncroft, C., B. Hoskins, and M. McIntyre, 1993: Two paradigms of baroclinic-wave life-cycle behaviour. Quart. J. Roy. Meteor. Soc., 119, 17-55, https://doi.org/10.1002/qj.49711950903.

Trigo, R. M., F. Varino, A. M. Ramos, M. A. Valente, J. L. Zêzere, J. M. Vaquero, C. M. Gouveia, and A. Russo, 2014: The record precipitation and flood event in Iberia in December 1876: Description and synoptic analysis. Front. Earth Sci., 2, 3, https://doi.org/10.3389/FEART.2014.00003.

Warner, M. D., C. F. Mass, and E. P. Salathé Jr., 2012: Wintertime extreme precipitation events along the Pacific Northwest coast: Climatology and synoptic evolution. Mon. Wea. Rev., 140, 2021-2043, https://doi.org/10.1175/MWRD-11-00197.1.

- — , and - . 2015: Changes in winter atmospheric rivers along the North American west coast in CMIP5 climate models. J. Hydrometeor., 16, 118-128, https://doi.org/10.1175/ JHM-D-14-0080.1.

Woollings, T., A. Hannachi, and B. Hoskins, 2010: Variability of the North Atlantic eddy-driven jet stream. Quart. J. Roy. Meteor. Soc., 136, 856-868, https://doi.org/10.1002/qj.625.

Zavadoff, B. L., and B. P. Kirtman, 2019: North Atlantic summertime anticyclonic Rossby wave breaking: Climatology, impacts, and connections to the Pacific decadal oscillation. J. Climate, 32, 485-500, https://doi.org/10.1175/JCLI-D-180304.1.

Zhu, Y., and R. E. Newell, 1998: A proposed algorithm for moisture fluxes from atmospheric rivers. Mon. Wea. Rev., 126, 725-735, https://doi.org/10.1175/1520-0493(1998)126<0725: APAFMF $>2.0 . \mathrm{CO} ; 2$ 